\title{
Identification of Potential Markers for Differentiating Epithelial Ovarian Cancer from Ovarian Low Malignant Potential Tumors through Integrated Bioinformatics Analysis
}

\author{
Wende Hao \\ Capital Medical University \\ Hongyu Zhao \\ Capital Medical University \\ Zhefeng Li \\ Capital Medical University \\ Jie Li \\ Capital Medical University \\ Jiahao Guo \\ Capital Medical University \\ Qi Chen
}

Capital Medical University

Yan Gao

Capital Medical University

Meng Ren

Capital Medical University

Xiaoting Zhao

Capital Medical University

Wentao Yue ( $\nabla$ yuewt@ccmu.edu.cn )

Beijing Obstetrics and Gynecology Hospital https://orcid.org/0000-0002-5917-1125

Primary research

Keywords: Epithelial ovarian cancer, low malignant potential tumor, Integrated bioinformatical analysis, Chemicals, Diagnosis, Prognosis

Posted Date: October 23rd, 2020

DOI: https://doi.org/10.21203/rs.3.rs-95043/v1 
License: (c) (i) This work is licensed under a Creative Commons Attribution 4.0 International License. Read Full License 


\section{Abstract}

Background: Epithelial ovarian cancer (EOC) is one of the most deadly female malignancies and is often diagnosed in advanced stages. In contrast, ovarian low malignant potential (LMP) tumors with favorable prognosis are intermediate between benign and malignant tumors. However, the current accuracy in distinguishing these diseases is unsatisfactory, leading to delays or unnecessary treatments. Therefore, unveiling the molecular differences between LMP and EOC and identifying useful molecular markers may increase the accuracy of diagnosis and also provide a rational basis for the development of new therapeutic and preventive strategies for EOC.

Methods: In this study, three microarray data (GSE9899, GSE57477 and GSE27651) were integrated to explore the differentially expressed genes (DEGs) between LMP and EOC samples. Then, we performed Gene Ontology (GO) analysis and Kyoto Encyclopedia of Gene and Genome (KEGG) pathway analysis of these DEGs. Furthermore, 5 core genes were identified by protein-protein interaction (PPI) network analysis, receiver operating characteristic (ROC) analysis, survival and Pearson correlation analysis. Meanwhile, we also identified the potential function of these 5 genes in EOC through KEGG pathway enrichment analysis. Finally, chemical-core gene network construction was performed to identify the potential drugs or risk factors for EOC.

Results: A total of 234 DEGs were successfully screened, including 81 upregulated genes and 153 downregulated genes. KEGG-pathway analysis indicated that the upregulated DEGs were mainly enriched in Cell cycle and Oocyte meiosis, whereas the downregulated DEGs were enriched in Huntington's disease. As for $\mathrm{GO}$ analysis, the upregulated DEGs were mainly associated with Protein binding, Nucleoplasm and Nucleus, whereas the downregulated DEGs were highly enriched in Cilium, Microtubule, and Motile cilium. In addition, 5 core genes (CCNB1, KIF20A, ASPM, AURKA, and KIF23) were identified through proteinprotein interaction (PPI) network analysis, ROC analysis, survival and Pearson correlation analysis, which show better diagnostic efficiency and higher prognostic value for EOC. Furthermore, we identified the potential function of these 5 genes in EOC through KEGG pathway enrichment analysis and found that all 5 core genes were enriched in "DNA replication”, "Mismatch repair", "Fanconi anemia pathway”, "Cell cycle", "Homologous recombination" and "Nucleotide excision repair", and "DNA replication" was the key player in them all. Finally, NetworkAnalyst was used to identify top 15 chemicals that link with the 5 core genes. Among them, 11 chemicals were potential drugs and 4 chemicals were risk factors for EOC.

Conclusions: Based on an integrated analysis, we identified potential biomarkers, risk factors and drugs for EOC, which may open a new direction for EOC diagnosis, condition appraisal, prevention and treatment in future.

\section{Background}

Epithelial ovarian cancer (EOC), accounting for $75 \%$ of all ovarian tumors and $90-95 \%$ of ovarian malignancies, has been reported to be the common cause of death among women with gynecological 
cancer $[1,2]$. Moreover, more than $70 \%$ of EOC cases are diagnosed at an advanced stage due to their vague symptoms[3]. Although surgery and other treatments have been improved, the therapeutic effect and prognosis of advanced ovarian cancer patients are still very poor due to lack of early and effective detection methods $[4,5]$.

Unlike EOC, low malignant potential (LMP) tumor is a unique subtype of ovarian epithelial tumor with behavior characteristics intermediating between benign and malignant tumors, and accounts for $15 \%-20 \%$ of epithelial ovarian tumors[6, 7]. Meanwhile, as abnormal cells form in the tissue covering the ovary and lack invasion of the underlying stroma, LMP tumors are also called borderline malignant ovarian cancer[8]. Thus, the prognosis of LMP and EOC differ considerably due to their different invasiveness, with 5 -year survival rate $>90 \%$ for LMP versus a $<30 \%$ survival for advanced high-grade EOC $[9,10]$. Furthermore, considering that the average age of LMP occurrence is 40 years, a more conservative surgical management-unilateral oophorectomy should be considered in these patients, which is different from EOC[9, 11]. However, a portion of LMP tumors display diffuse non-invasive extraovarian implants, and accurate classification of those implants could be particularly difficult, especially for those lacking underlying normal tissue in the biopsy $[6,8]$. Moreover, approximately $20 \%-30 \%$ of cases initially diagnosed with LMP are eventually confirmed to be EOC[6]. Thus, it can be seen that the diagnosis based on histopathology without using molecular markers will lead to inaccurate diagnosis of LMP. Therefore, revealing the molecular differences between LMP and EOC and identifying potential molecular markers may increase the accuracy of diagnosis and also provide a rational basis for the development of new therapeutic and preventive strategies for EOC.

Recently, many integrated bioinformatical studies on EOC and normal samples have been proven to assist with exploring the biomarkers and the mechanisms underlying the tumorigenesis and progression of ovarian cancer[12-14]. However, current integrated bioinformatical studies on LMP and EOC may be insufficient[2].

In this study, differentially expressed genes (DEGs) between LMP and EOC were first screened based on three GEO datasets. Then, Kyoto Encyclopaedia of Genes and Genomes (KEGG) and Gene Ontology (GO) analyses were performed for these DEGs. Next, protein-protein interaction (PPI) construction were utilized to identify the hub genes. Furthermore, ROC analysis, survival and Pearson correlation analysis were performed to further validate core genes. Finally, the chemical-core gene network was constructed, and the top 15 related chemicals for EOC were identified.

\section{Materials And Methods}

\section{Data Source and Data Preprocessing}

Four gene expression profiles (GSE9899, GSE27651, GSE12172, and GSE57477) were obtained from the Gene expression omnibus (GEO) database (http://www. ncbi.nlm.nih.gov/geo). GSE9899 included 18 ovarian LMP tumors and 267 EOC samples, GSE27651 included 8 LMP tumors and 22 high-grade serous 
ovarian carcinomas, GSE12172 comprised 30 LMP tumors and 60 EOC samples, and GSE57477 included 6 LMP tumors and 46 serous ovarian adenocarcinomas. They were functioned by Affymetrix Human Genome U133 Plus 2.0 Array [transcript (gene) version] and Illumina HumanHT-12 V4.0 expression beadchip [transcript (gene) version][15, 16].

\section{Identification of DEGs}

The "limma" R language package was utilized to detect the DEGs between

LMP tumors and EOC in GEO database[17]. We set the adjusted $\mathrm{P}<0.05$ and

$\mid \log _{2} \mathrm{FCl}>1.0$ as the cutoff criteria. Then, the Venn software online (http://bioinf-

ogp.cnb.csic.es/tools/venny/) was used for identifying the common DEGs amongGSE9899, GSE57477 and GSE27651.

\section{Pathway Enrichment Analysis of DEGs}

Gene Ontology (GO) function and Kyoto Encyclopedia of Genes and Genomes (KEGG) pathway analysis were performed to predict the potential functions of the DEGs by using the Database for Annotation, Visualization and Integrated Discovery (DAVID; https://david.ncifcrf.gov/). The top 20 items of GO function pathways and all items of KEGG pathways were then presented in the form of bubble maps. These bubble plots were drawn using the ggplot2 $\mathrm{R}$ package based on P-value through the statistical software $R$ (version 4.0.2). $P<0.05$ was considered as statistical significance.

\section{PPI network construction and Functional Analysis}

STRING (http://www.string-db.org/) was used to build PPI network of the identified DEGs[18]. Moreover, Cytoscape software (version 3.8.0) visualized the results to show the relationship between DEGs. The molecular complex detection (MCODE) plugin was used to search for cluster subnets by setting the default parameters as follows: degree cutoff $=2$, node score cutoff $=0.2$, k-score $=2$, and max. depth $=$ $100[13]$. Then, functional pathway analysis of the genes in the hub module 1 were performed through the DAVID database. Meanwhile, the plug-in CytoHubba was applied to screen the top 20 potential hub genes by the topological algorithm Maximal Clique Centrality (MCC)[19].

\section{Genetic Information of the Top 20 Potential Hub Genes}

The cBioPortal (https://www.cbioportal.org/) online tool was used to present the genetic alteration information of the top 20 hub genes

\section{Validation of Hub Genes}

The expression levels of the hub genes between LMP tumors and EOC were verified using the GSE12172 database, and then the ROC curves were used to explore their differential diagnostic value. Meanwhile, the Kaplan-Meier analysis was used to analyze the prognosis of the hub genes in EOC, and the results were shown in the form of a survival prognosis forest map according to the hazard ratio (HR), $95 \%$ confidence interval $(95 \% \mathrm{Cl})$, and $\mathrm{P}$-value. $\mathrm{P}<0.05$ was considered statistically significance. 
Pearson correlation Analysis between 5 Core Genes' Expression and the Level of Different Immune Checkpoint Proteins

Through the ROC and survival analysis, we screened the top 5 core genes with better diagnostic efficiency and higher prognostic value for EOC. We further analyzed whether 5 core genes' expression is related to the level of different immune checkpoint proteins through the Gene Expression Profiling Interactive Analysis (GEPIA) database (http://gepia.cancer-pku.cn/detail.php) )[20]. Then, the types of immune checkpoint proteins that are positively correlated with gene expression were selected and shown in picture.

\section{KEGG Pathway Analysis of the 5 Core Genes}

The genes that were co-expressed with 5 core genes in EOC patients in the TCGA database were identified through cBioportal (http://cbioportal.org). Then, the co-expressed gene pairs with the Pearson correlation coefficient $\geq 0.3$ were selected for further KEGG Pathway Analysis through the DAVID database. The top ten enriched KEGG terms for each core gene were shown in the form of matrix bubble map based on fold enrichment through the community-driven bioinformatics data visualization platform Hiplot (https://hiplot.com.cn/basic/matrix-bubble).

\section{Chemical-Core Gene Network Construction}

Subsequently, the coexpression network of the 5 core genes and their related chemicals was analyzed through the open-source platform NetworkAnalyst (https://www.networkanalyst.ca/)[21], and then visualized by Cytoscape software.

\section{Results}

\section{Identification of DEGs}

Screening criteria based on adjusted $\mathrm{P}<0.05$ and $\left|\log _{2} \mathrm{FC}\right|>1.0, \mathrm{DEG}$ were screened between LMP and EOC samples in GSE27651, GSE57477, and GSE9899. The DEGs of each gene expression profile data were visualized using a volcano plot (Fig. 1a-c). Subsequently, 81 overlapping upregulated genes and 153 overlapping downregulated genes (Fig. 1d, e) were identified using Venn software online.

\section{GO function and KEGG pathway enrichment analysis}

For a further understanding of the three datasets' common DEGs, GO function and KEGG pathway enrichment analysis were carried out through DAVID database. Then, the bubble map was drawn using the ggplot2.R package for the top 20 significant biological processes and the entire pathways based on $p$ value. In KEGG analysis, the common upregulated genes were highly enriched in Cell cycle and Oocyte meiosis (Fig. 2a), while the common downregulated genes were enriched in Huntington's disease (Fig. 2b). In GO analysis, the common upregulated genes were highly enriched in Protein binding, 
Nucleoplasm and Nucleus (Fig. 2c), while the common downregulated genes were highly enriched in Cilium, Microtubule, and Motile cilium (Fig. 2d).

\section{PPI Network Construction and Cluster Analysis}

To construct the PPI network of the DEGs (81 up-regulated and 153 down-regulated) in EOC. the STRING database was used, and then the results were analyzed by the Cytoscape software. Three important functional modules were screened with the MCODE. Among them, cluster 1 contained 59 core proteins and got the highest score in these clusters (Fig. 3a), cluster 2 contained 15 proteins (Fig. 3b), and cluster 3 contained 5 proteins (Fig. 3c). We further performed the functional analysis of cluster 1. In KEGG analysis, the DEGs of cluster 1 were mostly enriched in Cell cycle and Oocyte meiosis (Fig. $3 \mathrm{~d}$ ). In GO analysis, the DEGs of cluster 1 were mostly enriched in Protein binding, Nucleoplasm and Nucleus (Fig. 3e).

\section{Hub Gene Identification and Their Genetic Alteration Information Analysis}

We further used the cytoHubba to rank genes in the PPI network from highest to lowest according to the topological algorithm maximal clique centrality (MCC). To include more genes of interest, we screened the top 20 hub genes for further analysis, which were also included in cluster 1. (Fig. 4a and Table S1). Subsequently, cBioPortal was used to determine the genetic alteration information of the 20 hub genes, as illustrated in Fig. 4B and 4C. The hub genes were altered in 154 (50\%) queried EOC patients or samples. PBK and AURKA were altered most often ( 9 and $9 \%$, respectively). These alterations included amplification, deep deletion, truncating mutation, missense mutation and inframe mutation (Fig. 4b). Among the different types of alterations, amplification accounted for the highest percentage (Fig. 4c)

\section{Hub Gene Validation}

To further demonstrate the effect of the top 20 genes, we performed the expression analysis of LMP tumors versus EOC in GSE12172 dataset. The results showed that all 20 hub genes were screened higher in EOC (Fig. 5a). Meanwhile, ROC curve analysis was implemented to evaluate the capacity of those hub genes to distinguish LMP tumors and EOC in GSE12172, and almost all hub genes exhibited excellent diagnostic efficiency (AUC >0.90) except for CENPF (AUC = 0.848) (Fig. 5b). Meanwhile, the prognostic information of the 20 hub genes for EOC was analyzed by the Kaplan-Meier plotter database. A survival prognosis forest map of these genes is shown in Fig. 5c. Among the 20 hub genes, 15 hub genes were significantly associated with the overall survival (OS) of EOC patients. Moreover, EOC patients with higher expression levels of CCNB1 [HR $=1.92(1.55-2.38), P=1.1 \mathrm{E}-09]$, KIF20A [HR = 1.34 (1.14-1.56), $\mathrm{P}=$ $0.0003]$, ASPM [HR $=1.33(1.14-1.55), P=0.0002]$, AURKA [HR $=1.33(1.17-1.53), P=0.000029]$ and KIF23 [HR $=1.31(1.13-1.52), P=0.0004]$ were significantly related to worse OS. 


\section{Pearson Correlation Between 5 Core Genes and Immune Checkpoint Proteins}

Through above analysis, we screened the top 5 core genes (including CCNB1, KIF20A, ASPM, AURKA, and KIF23) with better diagnostic efficiency and higher prognostic value for EOC. In order to further explore the function of the 5 core genes, we used the GEPIA database to assess the correlation between gene expression and different immune checkpoint proteins (PD-L1, PD-1, CTLA-4, TIGIT, LAG3 and TIM-3) in EOC samples. As shown in Fig. 6, CCNB1 expression was positively associated with the LAG3 $(R=0.11, p$ $=0.027$ ) and PD-L1 expression ( $R=0.11, p=0.021)$ (Fig. 6a, b). KIF23 expression was positively associated with PD-L1 expression ( $R=0.15, p=0.0025)$ (Fig. 6c). KIF20A expression was also positively associated with the PD-L1 expression ( $R=0.16, p=0.00097)$ (Fig. $6 \mathrm{~d}$ ). AURKA expression was positively associated with the TIM-3 $(R=0.13, p=0.0069)$ and LAG3 expression ( $R h o=0.14, p=0.0042)(F i g .6 e, f)$. The above results indicate that four in five core genes are closely related to the EOC immunosuppressive microenvironment, which could be one reason that they can be used as effective prognostic markers.

\section{KEGG Pathway Enrichment Analysis for 5 Core Genes}

Then, we identified the potential function of these 5 core genes in EOC through KEGG pathway enrichment analysis. As a result, we observed that all 5 hub genes were enriched in "DNA replication", "Mismatch repair", "Fanconi anemia pathway", "Cell cycle", "Homologous recombination" and "Nucleotide excision repair", and "DNA replication" was the key player in them all. Meanwhile, the top 3 enriched KEGG terms in them were "DNA replication", "Cell cycle", "Mismatch repair", "Homologous recombination" and "Proteasome". (Fig. 7).

\section{Chemical-Core Gene Network Analysis}

Then, NetworkAnalyst was applied to screen the related chemicals for the 5 core genes. Meanwhile, Cytoscape software was used to draw the chemical-core gene network. As illustrated in Fig. 8a, the interaction network consists of 5 core genes and 300 chemicals. Moreover, according to the top 20 nodes in the network ranked by their degree of connectivity using cytoHubba, we found that most chemicals were related to CCNB1 (degree score $=246$ ), AURKA (degree score $=86$ ), and KIF20A (degree score $=67$ ) (table S2 and Fig. 8a), followed by ASPM (degree score $=63$ ) and KIF23 (degree score $=52$ ). Furthermore, the top 15 chemicals screened by Cytoscape were found to be related with all five genes (Fig. 8b)

\section{Discussion}

Invasiveness is one of the aggressive features of EOC, particularly the advanced high-grade disease. In contrast, LMP tumors often behave as a located lesion within the tissue covering the ovary[22]. Although most of LMP tumors will keep a mild status for a long period, a certain proportion of them display noninvasive extra-ovarian implants and also possess the potential to progress into invasive ovarian cancer[23,24]. Moreover, the borderline category of ovarian tumors (LMP) is an ongoing challenging and 
controversial area in gynecologic pathology due to difficulty in accurate classification of implants[25]. Thus, the lack of accurate markers for distinguishing EOC from LMP will lead to incorrect diagnosis, inappropriate treatment and adverse consequences. In this study, we integrated three gene chips from GEO databases and selected 234 DEGs (including 81 upregulated DEGs and 152 downregulated DEGs) between LMP and EOC samples, and further functional analysis was performed.

The KEGG analysis displayed that the common upregulated DEGs were mainly enriched in Cell cycle and Oocyte meiosis, while the common downregulated genes were enriched in Huntington's disease. In addition, the GO analysis showed that the common upregulated DEGs were mainly associated with Protein binding, Nucleoplasm and Nucleus, while the common downregulated genes were mainly associated with Cilium, Microtubule, and Motile cilium. Indeed, many studies have indicated that the Cell cycle[26, 27], Oocyte meiosis[28, 29], Protein binding[30, 31], Nucleoplasm[32, 33], Nucleus[34], Microtubule[35, 36], Cilium and Motile cilium[37, 38] are highly associated with the tumorigenesis and progression of EOC. However, the association between Huntington's disease and EOC still remains unclear. In brief, these functional enrichment results have certain guiding significance. Furthermore, a PPI network was constructed based on the DEGs, and then the MCODE plug-in filtered out three related clusters. We further performed functional analysis of cluster 1 and found that the results are consistent with the previous analysis. Next, 20 hub genes with the highest degrees of connectivity in the PPI network were identified through the CytoHubba plug-in. Subsequently, the GSE12172 dataset was used to further verify the expression levels of these hub genes in LMP and EOC samples, and the results showed that all hub genes were higher expressed in EOC tissues compared with LMP tumors, meaning that these genes may be crucial to tumorigenesis and progression in EOC. Meanwhile, ROC curve analysis demonstrated that all these genes had better diagnostic efficiency for differentiating EOC from LMP tumors. In addition, survival analysis of these hub genes demonstrated that 5 upregulated genes (CCNB1, KIF20A, ASPM, AURKA, and KIF23) were significantly associated with a poorer OS in EOC patients, which may be partly attributed to the tumor immunosuppressive microenvironment when performing the Pearson correlation analysis between 5 core genes' expression and the level of different immune checkpoint proteins. In order to further understand the biological functions of these 5 genes in EOC, we performed the KEGG pathway enrichment analysis for them. As a result, we observed that all 5 core genes were enriched in "DNA replication", "Mismatch repair", "Fanconi anemia pathway", "Cell cycle", "Homologous recombination" and "Nucleotide excision repair", and "DNA replication" was the key player in them all. Meanwhile, the top 3 enriched KEGG terms in them were "DNA replication", "Cell cycle", "Mismatch repair", "Homologous recombination" and "Proteasome". Next, the 5 core genes and their current researches in ovarian cancer were introduced as follows.

CCNB1, also called Cyclin B1, is an important mitotic cyclin and produce complexes with p34(cdc2), which function in the $\mathrm{G} 2$ and $\mathrm{M}$ phases of the cell cycle[39]. Meanwhile, the overexpression of CCNB1 has been reported in many tumors, including EOC[40-43], and a plenty of studies revealed that cyclin B1 is implicated in the differentiation, proliferation, apoptosis, metastasis and chemoresistance of ovarian cancer cell[44-46]. 
Kinesin family member 20A (KIF20A), a member of the kinesin superfamily-6, is a microtubule-associated motor protein localized to the Golgi apparatus that is required for cell cycle mitosis[47, 48]. Recently, KIF20A has been reported to be involved in the proliferation of EOC, and also could be served as a useful prognostic biomarker for EOC patients[49-51].

Abnormal spindle-like microcephaly-associated (ASPM) gene, also called as abnormal spindle microtubule assembly, is located on chromosome 1q31 and encodes the ASPM protein[52]. Many studies have reported that ASPM is highly expressed in a variety of cancers and is related to poor clinical prognosis, including EOC[53-56].

AURKA, as a family of serine/threonine kinases, localizes to centrosomes and mitotic spindles where it mediates mitotic progression and chromosomal stability[57]. Mounting evidence suggests that AURKA is involved in the tumorigenesis and progression of EOC[58-61].

KIF23, a human homolog of mouse Kif23, is a member of kinesin motor protein involved in the regulation of cytokinesis[62,63]. Recently, Tong Lia et al has showed that KIF23 was mainly related to cell cycle and positively associated with poor prognosis in EOC patients. Meanwhile, they also found that both miR-424$5 p$ and miR-503-5p can directly targeted to 3 'UTR of KIF23 to suppress the expression of KIF23 and inhibit ovarian cancer cell proliferation and migration[64].

Finally, NetworkAnalyst was applied to screen the chemicals that were associated with the 5 core genes and we found that CCNB1, AURKA, and KIF20A were clearly the three interactive core genes that link most chemicals. Moreover, the top 15 chemicals screened by Cytoscape were found to be related with all 5 genes. Among them, valproic acid[65, 66], Calcitriol[67, 68], cobaltous chloride[69], Copper Sulfate[70, 71], Genistein[72], 7,8-Dihydro-7,8-dihydroxybenzo(a)pyrene 9,10-oxide[73], Methotrexate[74], Mustard Gas[75] and Cyclosporine[76] all have been showed to have antitumor activity against EOC in vitro or vivo, whereas bisphenol A[77, 78], cadmium[79, 80], Aflatoxin B1[81] and Estradiol[82, 83] all have cancerpromoting activity in EOC. However, Lucanthone and Latex have not been studied in EOC till now despite they showed anti-cancer effects in other cancers $[84,85]$. Thus, additional studies and clinical trials are needed to identify and explore their effect on EOC in future.

\section{Conclusions}

In brief, by performing an integrated bioinformatic analysis of three GEO datasets, we identified five core genes with better diagnostic efficiency and higher prognostic value for EOC. Meanwhile, our study also screened the potential drugs or risk factors for EOC through chemical-core gene network analysis. However, there are still some limitations in this study. Since our study is based on data analysis, a large number of clinical samples and biological experiments are urgently needed to verify our results.

Furthermore, we will design experiments based on in-depth molecular mechanisms of the core genes and potential risk factors or drugs for EOC, and improve the deficiencies. 


\section{Abbreviations}

EOC: Epithelial ovarian cancer; LMP: ovarian low malignant potential tumors; GO: Gene Ontology; KEGG: Kyoto Encyclopedia of Gene and Genome; PPI: protein-protein interaction; DEGs: differentially expressed genes; MCODE: molecular complex detection; MCC: Maximal Clique Centrality; HR: hazard ratio; OS: overall survival; GEO: Gene expression omnibus; ROC: Receiver operating characteristic; TCGA: the Cancer Genome Atlas.

\section{Declarations}

\section{Acknowledgments}

The authors sincerely thank the researchers for providing their GEO databases information online, it is our pleasure to acknowledge their contributions.

\section{Authors' contributions}

WH designed the study and drafted the manuscript. HZ and JG performed the data collecting and analysis. ZL, JL, QC, YG and MR participated in the data interpretation and study design. As the corresponding authors, WY and XZ was responsible for critical revision of the manuscript and has full access to all data and the final decision to submit the article for publication. All authors read and approved the final manuscript.

\section{Funding}

This work was supported by Beijing Municipal Science \& Technology Commission (grant number: Z181100001718193) and The National Natural Science Foundation of China (grant numbers: 81672838 and 61431019).

\section{Availability of data and materials}

All data generated or analyzed during this study are included in this article.

\section{Ethics approval and consent to participate}

This manuscript is based on the database of GEO, so all procedures performed in our study involving human participants were in accordance with the 1964 Helsinki declaration and its later amendments or comparable ethical standards. Meanwhile,

this manuscript does not involve an informed consent due to the data in our study from the GEO database.

\section{Consent for publication}


All authors approved the publication of this paper.

\section{Competing interests}

The authors declare that they have no conflict of interest.

\section{References}

1. To SKY, Mak ASC, Eva Fung YM, Che C-M, Li S-S, Deng W, et al. $\beta$-catenin downregulates Dicer to promote ovarian cancer metastasis. Oncogene. 2017;36:5927-38. https://doi.org/10.1038/onc.2017.185.

2. Zhou Y, Layton O, Hong L. Identification of Genes and Pathways Involved in Ovarian Epithelial Cancer by Bioinformatics Analysis. J Cancer. 2018 Jul 30;9(17):3016-3022. doi: 10.7150/jca.26133.

3. Maringe C, Walters S, Butler J, Coleman MP, Hacker N, Hanna L, et al. Stage at diagnosis and ovarian cancer survival: evidence from the International Cancer Benchmarking Partnership. Gynecol Oncol. 2012;127:75-82. https://doi.org/10.1016/j.ygyno.2012.06.033.

4. Jayson GC, Kohn EC, Kitchener HC, Ledermann JA. Ovarian cancer. Lancet. 2014;384:1376-88. https://doi.org/10.1016/S0140-6736(13)62146-7.

5. La Vecchia C. Ovarian cancer: epidemiology and risk factors. European Journal of Cancer Prevention: The Official Journal of the European Cancer Prevention Organisation (ECP). 2017;26:5562. https://doi.org/10.1097/CEJ.0000000000000217.

6. Seong SJ, Kim DH, Kim MK, Song T. Controversies in borderline ovarian tumors. Journal of Gynecologic Oncology. 2015;26:343-9. https://doi.org/10.3802/jgo.2015.26.4.343.

7. Skírnisdóttir I, Garmo H, Wilander E, Holmberg L. Borderline ovarian tumors in Sweden 1960-2005: trends in incidence and age at diagnosis compared to ovarian cancer. Int J Cancer. 2008;123:1897901. https://doi.org/10.1002/ijc.23724.

8. Hanna RK, Soper JT, Notes P, Livasy C. Ovarian Tumors of Low Malignant Potential 2010:110-20.

9. Zhang Q, Yu S, lan S, Lok S, Sze A, Wong T, et al. FAM83D promotes ovarian cancer progression and its potential application in diagnosis of invasive ovarian cancer 2019:4569-81. https://doi.org/10.1111/jcmm.14360.

10. Hauptmann S, Friedrich K, Redline R, Avril S. Ovarian borderline tumors in the 2014 WHO classification: evolving concepts and diagnostic criteria. Virchows Archiv: An International Journal of Pathology. 2017;470:125-42. https://doi.org/10.1007/s00428-016-2040-8.

11. Aluloski I, Tanturovski M, Jovanovic R, Kostadinova-Kunovska S, Petrusevska G, Stojkovski I, et al. Survival of Advanced Stage High-Grade Serous Ovarian Cancer Patients in the Republic of Macedonia. Open Access Macedonian Journal of Medical Sciences. 2017;5:904-8. https://doi.org/10.3889/oamjms.2017.215.

12. Liu J, Meng H, Li S, Shen Y, Wang H, Shan W, et al. Identification of Potential Biomarkers in Association With Progression and Prognosis in Epithelial Ovarian Cancer by Integrated. 
Bioinformatics Analysis. 2019;10:1-16. https://doi.org/10.3389/fgene.2019.01031.

13. Yang D, He Y, Wu B, Deng Y, Wang N, Li M, et al. Integrated bioinformatics analysis for the screening of hub genes and therapeutic drugs in ovarian cancer 2020:1-18.

14. Zheng M-J, Li X, Hu Y-X, Dong H, Gou R, Nie X, et al. Identification of molecular marker associated with ovarian cancer prognosis using bioinformatics analysis and experiments. J Cell Physiol. 2019;234:11023-36. https://doi.org/10.1002/jcp.27926.

15. Harbig J, Sprinkle R, Enkemann SA. A sequence-based identification of the genes detected by probesets on the Affymetrix U133 plus 2.0 array. Nucleic Acids Res. 2005;33:e31. https://doi.org/10.1093/nar/gni027.

16. Jönsson J-M, Johansson I, Dominguez-Valentin M, Kimbung S, Jönsson M, Bonde JH, et al. Molecular subtyping of serous ovarian tumors reveals multiple connections to intrinsic breast cancer subtypes. PloS One. 2014;9:e107643. https://doi.org/10.1371/journal.pone.0107643.

17. Ritchie ME, Phipson B, Wu D, Hu Y, Law CW, Shi W, et al. limma powers differential expression analyses for RNA-sequencing and microarray studies. Nucleic Acids Res. 2015;43:e47. https://doi.org/10.1093/nar/gkv007.

18. Szklarczyk D, Franceschini A, Wyder S, Forslund K, Heller D, Huerta-Cepas J, et al. STRING v10: protein-protein interaction networks, integrated over the tree of life. Nucleic Acids Res. 2015;43:D44752. https://doi.org/10.1093/nar/gku1003.

19. Chin $\mathrm{C}-\mathrm{H}$, Chen S-H, Wu H-H, Ho C-W, Ko M-T, Lin C-Y. cytoHubba: identifying hub objects and subnetworks from complex interactome. BMC Systems Biology 2014;8 Suppl 4:S11. https://doi.org/10.1186/1752-0509-8-S4-S11.

20. Chen L, Zhao T. Identification of KHSRP-Regulated RNAs in Esophagus Cancer by Integrated Bioinformatics Analysis. Cancer Biother Radiopharm. 2020 Jul 14. doi:10.1089/cbr.2020.3745.

21. Zhou G, Soufan O, Ewald J, Hancock REW, Basu N, Xia J. NetworkAnalyst 3.0: a visual analytics platform for comprehensive gene expression profiling and meta-analysis. Nucleic Acids Res. 2019;47:W234-41. https://doi.org/10.1093/nar/gkz240.

22. Fischerova D, Zikan M, Dundr P, Cibula D. Diagnosis, treatment, and follow-up of borderline ovarian tumors. Oncologist. 2012;17:1515-33. https://doi.org/10.1634/theoncologist.2012-0139.

23. Cadron I, Leunen K, Van Gorp T, Amant F, Neven P, Vergote I. Management of borderline ovarian neoplasms. Journal of Clinical Oncology: Official Journal of the American Society of Clinical Oncology. 2007;25:2928-37. https://doi.org/10.1200/JC0.2007.10.8076.

24. Fukumoto M, Nakayama K. Ovarian epithelial tumors of low malignant potential: Are they precursors of ovarian carcinoma ? POTENTIAL 2006:233-9. https://doi.org/10.1111/j.14401827.2006.01960.x.

25. Kayikçioglu F, Pata O, Cengiz S, Tulunay G, Boran N, Yalvaç S, et al. Accuracy of frozen section diagnosis in borderline ovarian malignancy. Gynecol Obstet Invest. 2000;49:187-9. https://doi.org/10.1159/000010244. 
26. Ivy SP, Kunos CA, Arnaldez Fl, Kohn EC. Defining and targeting wild-type BRCA high-grade serous ovarian cancer: DNA repair and cell cycle checkpoints. Expert Opin Investig Drugs. 2019;28:771-85. https://doi.org/10.1080/13543784.2019.1657403.

27. Lee J-M, Minasian L, Kohn EC. New strategies in ovarian cancer treatment. Cancer. 2019;125(Suppl 24):4623-9. https://doi.org/10.1002/cncr.32544.

28. Li W, Liu Z, Liang B, Chen S, Zhang X, Tong X, et al. Identification of core genes in ovarian cancer by an integrative meta-analysis. Journal of Ovarian Research. 2018;11:94. https://doi.org/10.1186/s13048-018-0467-z.

29. Lee S-Y, Kwon J, Woo JH, Kim K-H, Lee K-A. Bcl2/10 mediates the proliferation, invasion and migration of ovarian cancer cells. Int J Oncol. 2020;56:618-29.

https://doi.org/10.3892/ijo.2019.4949.

30. Zhao L, Wang Z-G, Zhang P, Yu X-F, Su X-J. Poly r(C) Binding Protein 1 Regulates Posttranscriptional Expression of the Ubiquitin Ligase TRIM56 in Ovarian Cancer. IUBMB Life. 2019;71:177-82. https://doi.org/10.1002/iub.1948.

31. Yan H, Silva MA, Li H, Zhu L, Li P, Li X, et al. Long noncoding RNA DQ786243 interacts with miR-506 and promotes progression of ovarian cancer through targeting CAMP responsive element binding protein 1. J Cell Biochem. 2018;119:9764-80. https://doi.org/10.1002/jcb.27295.

32. Brachner A, Foisner R. Lamina-associated polypeptide (LAP)2 $\alpha$ and other LEM proteins in cancer biology. Adv Exp Med Biol. 2014;773:143-63. https://doi.org/10.1007/978-1-4899-8032-8_7.

33. Wu P-H, Hung S-H, Ren T, Shih I-M, Tseng Y. Cell cycle-dependent alteration in NAC1 nuclear body dynamics and morphology. Phys Biol. 2011;8:15005. https://doi.org/10.1088/14783975/8/1/015005.

34. Deuster E, Mayr D, Hester A, Kolben T, Zeder-Göß C, Burges A, et al. Correlation of the Aryl Hydrocarbon Receptor with FSHR in Ovarian Cancer Patients. Int J Mol Sci 2019;20. https://doi.org/10.3390/ijms20122862.

35. McGrail DJ, Khambhati NN, Qi MX, Patel KS, Ravikumar N, Brandenburg CP, et al. Alterations in ovarian cancer cell adhesion drive taxol resistance by increasing microtubule dynamics in a FAKdependent manner. Sci Rep. 2015;5:9529. https://doi.org/10.1038/srep09529.

36. Chan A, Singh AJ, Northcote PT, Miller JH. Peloruside A. a microtubule-stabilizing agent, induces aneuploidy in ovarian cancer cells. Invest New Drugs. 2016;34:424-38. https://doi.org/10.1007/s10637-016-0355-6.

37. Rohozinski J, Diaz-Arrastia C, Edwards CL. Do some epithelial ovarian cancers originate from a fallopian tube ciliate cell lineage? Med Hypotheses. 2017;107:16-21. https://doi.org/10.1016/j.mehy.2017.07.014.

38. Sumi T, Ishiko O, Maeda K, Haba T, Wakasa K, Ogita S. Adenocarcinoma arising from respiratory ciliated epithelium in mature ovarian cystic teratoma. Arch Gynecol Obstet. 2002;267:107-9. https://doi.org/10.1007/s004040100244. 
39. Wang A, Yoshimi N, Ino N, Tanaka T, Mori H. Overexpression of cyclin B1 in human colorectal cancers. J Cancer Res Clin Oncol. 1997;123:124-7. https://doi.org/10.1007/BF01269891.

40. Agarwal R, Gonzalez-Angulo A-M, Myhre S, Carey M, Lee J-S, Overgaard J, et al. Integrative analysis of cyclin protein levels identifies cyclin b1 as a classifier and predictor of outcomes in breast cancer. Clinical Cancer Research: An Official Journal of the American Association for Cancer Research. 2009;15:3654-62. https://doi.org/10.1158/1078-0432.CCR-08-3293.

41. Li J-Q, Kubo A, Wu F, Usuki H, Fujita J, Bandoh S, et al. Cyclin B1, unlike cyclin G1, increases significantly during colorectal carcinogenesis and during later metastasis to lymph nodes. Int $\mathrm{J}$ Oncol. 2003;22:1101-10.

42. Soria JC, Jang SJ, Khuri FR, Hassan K, Liu D, Hong WK, et al. Overexpression of cyclin B1 in earlystage non-small cell lung cancer and its clinical implication. Can Res. 2000;60:4000-4.

43. Raab M, Sanhaji M, Zhou S, Rödel F, El-Balat A, Becker S, et al. Blocking Mitotic Exit of Ovarian Cancer Cells by Pharmaceutical Inhibition of the Anaphase-Promoting Complex Reduces Chromosomal Instability. Neoplasia (New York NY). 2019;21:363-75. https://doi.org/10.1016/j.neo.2019.01.007.

44. Fei F, Qu J, Liu K, Li C, Wang X, Li Y, et al. The subcellular location of cyclin B1 and CDC25 associated with the formation of polyploid giant cancer cells and their clinicopathological significance. Laboratory Investigation; a Journal of Technical Methods Pathology. 2019;99:483-98. https://doi.org/10.1038/s41374-018-0157-x.

45. Nguyen TMH, Shin I-W, Lee TJ, Park J, Kim JH, Park MS, et al. Loss of ITM2A, a novel tumor suppressor of ovarian cancer through $\mathrm{G} 2 / \mathrm{M}$ cell cycle arrest, is a poor prognostic factor of epithelial ovarian cancer. Gynecol Oncol. 2016;140:545-53. https://doi.org/10.1016/j.ygyno.2015.12.006.

46. Chang C-C, Hung C-M, Yang Y-R, Lee M-J, Hsu Y-C. Sulforaphane induced cell cycle arrest in the G2/M phase via the blockade of cyclin B1/CDC2 in human ovarian cancer cells. Journal of Ovarian Research. 2013;6:41. https://doi.org/10.1186/1757-2215-6-41.

47. Yan G-R, Zou F-Y, Dang B-L, Zhang Y, Yu G, Liu X, et al. Genistein-induced mitotic arrest of gastric cancer cells by downregulating KIF20A, a proteomics study. Proteomics. 2012;12:2391-9. https://doi.org/10.1002/pmic.201100652.

48. Zhang Y, Liu J, Peng X, Zhu C-C, Han J, Luo J, et al. KIF20A regulates porcine oocyte maturation and early embryo development. PloS One. 2014;9:e102898. https://doi.org/10.1371/journal.pone.0102898.

49. Li H, Zhang W, Sun X, Chen J, Li Y, Niu C, et al. Overexpression of kinesin family member 20A is associated with unfavorable clinical outcome and tumor progression in epithelial ovarian cancer. Cancer Management Research. 2018;10:3433-50. https://doi.org/10.2147/CMAR.S169214.

50. Kawai Y, Shibata K, Sakata J, Suzuki S, Utsumi F, Niimi K, et al. KIF20A expression as a prognostic indicator and its possible involvement in the proliferation of ovarian clear-cell carcinoma cells. Oncol Rep. 2018;40:195-205. https://doi.org/10.3892/or.2018.6401. 
51. Li Y, Guo H, Wang Z, Bu H, Wang S, Wang H, et al. Cyclin F and KIF20A, FOXM1 target genes, increase proliferation and invasion of ovarian cancer cells. Exp Cell Res. 2020;395:112212. https://doi.org/10.1016/j.yexcr.2020.112212.

52. Xu Z, Zhang Q, Luh F, Jin B, Liu X. Overexpression of the ASPM gene is associated with aggressiveness and poor outcome in bladder cancer. Oncology Letters. 2019;17:1865-76. https://doi.org/10.3892/ol.2018.9762.

53. Zhou J-W, Wang H, Sun W, Han N-N, Chen L. ASPM is a predictor of overall survival and has therapeutic potential in endometrial cancer. American Journal of Translational Research. 2020;12:1942-53.

54. Yuan Y-J, Sun Y, Gao R, Yin Z-Z, Yuan Z-Y, Xu L-M. Abnormal spindle-like microcephaly-associated protein (ASPM) contributes to the progression of Lung Squamous Cell Carcinoma (LSCC) by regulating CDK4. J Cancer. 2020;11:5413-23. https://doi.org/10.7150/jca.39760.

55. Brüning-Richardson A, Bond J, Alsiary R, Richardson J, Cairns DA, McCormack L, et al. ASPM and microcephalin expression in epithelial ovarian cancer correlates with tumour grade and survival. $\mathrm{Br} J$ Cancer. 2011;104:1602-10. https://doi.org/10.1038/bjc.2011.117.

56. Alsiary R, Brüning-Richardson A, Bond J, Morrison EE, Wilkinson N, Bell SM. Deregulation of microcephalin and ASPM expression are correlated with epithelial ovarian cancer progression. PloS One. 2014;9:e97059. https://doi.org/10.1371/journal.pone.0097059.

57. Gautschi O, Heighway J, Mack PC, Purnell PR, Lara PNJ, Gandara DR. Aurora kinases as anticancer drug targets. Clinical Cancer Research: An Official Journal of the American Association for Cancer Research. 2008;14:1639-48. https://doi.org/10.1158/1078-0432.CCR-07-2179.

58. Do T-V, Xiao F, Bickel LE, Klein-Szanto AJ, Pathak HB, Hua X, et al. Aurora kinase A mediates epithelial ovarian cancer cell migration and adhesion. Oncogene. 2014;33:539-49. https://doi.org/10.1038/onc.2012.632.

59. Wang C, Yan Q, Hu M, Qin D, Feng Z. Effect of AURKA Gene Expression Knockdown on Angiogenesis and Tumorigenesis of Human Ovarian Cancer Cell Lines. Targeted Oncology. 2016;11:771-81. https://doi.org/10.1007/s11523-016-0436-7.

60. Kulbe H, Otto R, Darb-Esfahani S, Lammert H, Abobaker S, Welsch G, et al. Discovery and Validation of Novel Biomarkers for Detection of Epithelial Ovarian Cancer. Cells 2019;8. https://doi.org/10.3390/cells8070713.

61. Yang G, Chang B, Yang F, Guo X, Cai KQ, Xiao XS, et al. Aurora kinase A promotes ovarian tumorigenesis through dysregulation of the cell cycle and suppression of BRCA2. Clinical Cancer Research: An Official Journal of the American Association for Cancer Research. 2010;16:3171-81. https://doi.org/10.1158/1078-0432.CCR-09-3171.

62. Nislow C, Lombillo VA, Kuriyama R, McIntosh JR. A plus-end-directed motor enzyme that moves antiparallel microtubules in vitro localizes to the interzone of mitotic spindles. Nature. 1992;359:543-7. https://doi.org/10.1038/359543a0. 
63. Li X-L, Ji Y-M, Song R, Li X-N, Guo L-S. KIF23 Promotes Gastric Cancer by Stimulating Cell Proliferation. Dis Markers. 2019;2019:9751923. https://doi.org/10.1155/2019/9751923.

64. Li T, Li Y, Gan Y, Tian R, Wu Q, Shu G, et al. Methylation-mediated repression of MiR-424/503 cluster promotes proliferation and migration of ovarian cancer cells through targeting the hub gene KIF23. Cell Cycle. 2019;18:1601-18. https://doi.org/10.1080/15384101.2019.1624112.

65. Sajadpoor Z, Amini-Farsani Z, Teimori H, Shamsara M, Sangtarash MH, Ghasemi-Dehkordi P, et al. Valproic Acid Promotes Apoptosis and Cisplatin Sensitivity Through Downregulation of H19 Noncoding RNA in Ovarian A2780 Cells. Appl Biochem Biotechnol. 2018;185:1132-44. https://doi.org/10.1007/s12010-017-2684-0.

66. Kwiecińska P, Taubøll E, Grzyb E, Fiedor E, Ptak A, Gregoraszczuk EL. Valproic Acid as a Promising Co-Treatment With Paclitaxel and Doxorubicin in Different Ovarian Carcinoma Cell Lines. International Journal of Gynecological Cancer: Official Journal of the International Gynecological Cancer Society. 2016;26:1546-56. https://doi.org/10.1097/IGC.0000000000000814.

67. Yeung T-L, Sheng J, Leung CS, Li F, Kim J, Ho SY, et al. Systematic Identification of Druggable Epithelial-Stromal Crosstalk Signaling Networks in Ovarian Cancer. J Natl Cancer Inst. 2019;111:272-82. https://doi.org/10.1093/jnci/djy097.

68. Kavandi L, Collier MA, Nguyen H, Syed V. Progesterone and calcitriol attenuate inflammatory cytokines CXCL1 and CXCL2 in ovarian and endometrial cancer cells. J Cell Biochem. 2012;113:3143-52. https://doi.org/10.1002/jcb.24191.

69. Gao F, Chattopadhyay A, Navab M, Grijalva V, Su F, Fogelman AM, et al. Apolipoprotein A-I mimetic peptides inhibit expression and activity of hypoxia-inducible factor-1a in human ovarian cancer cell lines and a mouse ovarian cancer model. The Journal of Pharmacology Experimental Therapeutics. 2012;342:255-62. https://doi.org/10.1124/jpet.112.191544.

70. Burki HR, Okita GT. Effect of oral copper sulfate on 7,12-dimethylbenz(alpha)anthracene carcinogenesis in mice. Br J Cancer. 1969;23:591-6. https://doi.org/10.1038/bjc.1969.73.

71. Patankar NA, Waterhouse D, Strutt D, Anantha M, Bally MB. Topophore C: a liposomal nanoparticle formulation of topotecan for treatment of ovarian cancer. Invest New Drugs. 2013;31:46-58. https://doi.org/10.1007/s10637-012-9832-8.

72. Ning Y, Feng W, Cao X, Ren K, Quan M, Chen A, et al. Genistein inhibits stemness of SKOV3 cells induced by macrophages co-cultured with ovarian cancer stem-like cells through IL-8/STAT3 axis. Journal of Experimental Clinical Cancer Research: CR. 2019;38:19. https://doi.org/10.1186/s13046018-1010-1.

73. Jeffy BD, Schultz EU, Selmin O, Gudas JM, Bowden GT, Romagnolo D. Inhibition of BRCA-1 expression by benzo[a]pyrene and its diol epoxide. Molecular Carcinogenesis 1999;26:100-18. https://doi.org/10.1002/(sici)1098-2744(199910)26:2<100::aid-mc5>3.0.co;2-1.

74. Pantshwa JM, Rhoda K, Clift SJ, Pradeep P, Choonara YE, Kumar P, et al. Chemotherapeutic Efficacy of Implantable Antineoplastic-Treatment Protocols in an Optimal Mouse Model for Human Ovarian Carcinoma Cell Targeting. Int J Mol Sci 2018;19. https://doi.org/10.3390/ijms19103030. 
75. Anand P, Sundaram C, Jhurani S, Kunnumakkara AB, Aggarwal BB. Curcumin and cancer: an «oldage» disease with an «age-old» solution. Cancer Lett. 2008;267:133-64. https://doi.org/10.1016/j.canlet.2008.03.025.

76. Yu T, Yang Y, Zhang J, He H, Ren X. Circumvention of cisplatin resistance in ovarian cancer by combination of cyclosporin A and low-intensity ultrasound. European Journal of Pharmaceutics Biopharmaceutics: Official Journal of Arbeitsgemeinschaft Fur Pharmazeutische Verfahrenstechnik eV. 2015;91:103-10. https://doi.org/10.1016/j.ejpb.2015.02.003.

77. Hui L, Li H, Lu G, Chen Z, Sun W, Shi Y, et al. Low Dose of Bisphenol A Modulates Ovarian Cancer Gene Expression Profile and Promotes Epithelial to Mesenchymal Transition Via Canonical Wnt Pathway. Toxicological Sciences: An Official Journal of the Society of Toxicology. 2018;164:527-38. https://doi.org/10.1093/toxsci/kfy107.

78. Shi X-Y, Wang Z, Liu L, Feng L-M, Li N, Liu S, et al. Low concentrations of bisphenol A promote human ovarian cancer cell proliferation and glycolysis-based metabolism through the estrogen receptor-a pathway. Chemosphere. 2017;185:361-7. https://doi.org/10.1016/j.chemosphere.2017.07.027.

79. Eriksen KT, Halkjær J, Sørensen M, Meliker JR, McElroy JA, Tjønneland A, et al. Dietary cadmium intake and risk of breast, endometrial and ovarian cancer in Danish postmenopausal women: a prospective cohort study. PloS One. 2014;9:e100815. https://doi.org/10.1371/journal.pone.0100815.

80. Adams SV, Quraishi SM, Shafer MM, Passarelli MN, Freney EP, Chlebowski RT, et al. Dietary cadmium exposure and risk of breast, endometrial, and ovarian cancer in the Women's Health Initiative. Environ Health Perspect. 2014;122:594-600. https://doi.org/10.1289/ehp.1307054.

81. Żołnierczyk AK, Mączka WK, Grabarczyk M, Wińska K, Woźniak E, Anioł M. IsoxanthohumolBiologically active hop flavonoid. Fitoterapia. 2015;103:71-82. https://doi.org/10.1016/j.fitote.2015.03.007.

82. Valladares M, Plaza-Parrochia F, Lépez M, López D, Gabler F, Gayan P, et al. Effect of estradiol on the expression of angiogenic factors in epithelial ovarian cancer. Histol Histopathol. 2017;32:1187-96. https://doi.org/10.14670/HH-11-874.

83. Li H-H, Zhao Y-J, Li Y, Dai C-F, Jobe SO, Yang X-S, et al. Estradiol $17 \beta$ and its metabolites stimulate cell proliferation and antagonize ascorbic acid-suppressed cell proliferation in human ovarian cancer cells. Reproductive Sciences (Thousand Oaks Calif). 2014;21:102-11. https://doi.org/10.1177/1933719113492211.

84. Carew JS, Espitia CM, Esquivel JA 2nd, Mahalingam D, Kelly KR, Reddy G, et al. Lucanthone is a novel inhibitor of autophagy that induces cathepsin D-mediated apoptosis. The Journal of Biological Chemistry. 2011;286:6602-13. https://doi.org/10.1074/jbc.M110.151324.

85. Basu P, Meza E, Bergel M, Maier C. Estrogenic. Antiestrogenic and Antiproliferative Activities of Euphorbia bicolor (Euphorbiaceae) Latex Extracts and Its Phytochemicals. Nutrients 2019;12. https://doi.org/10.3390/nu12010059. 


\section{Figures}
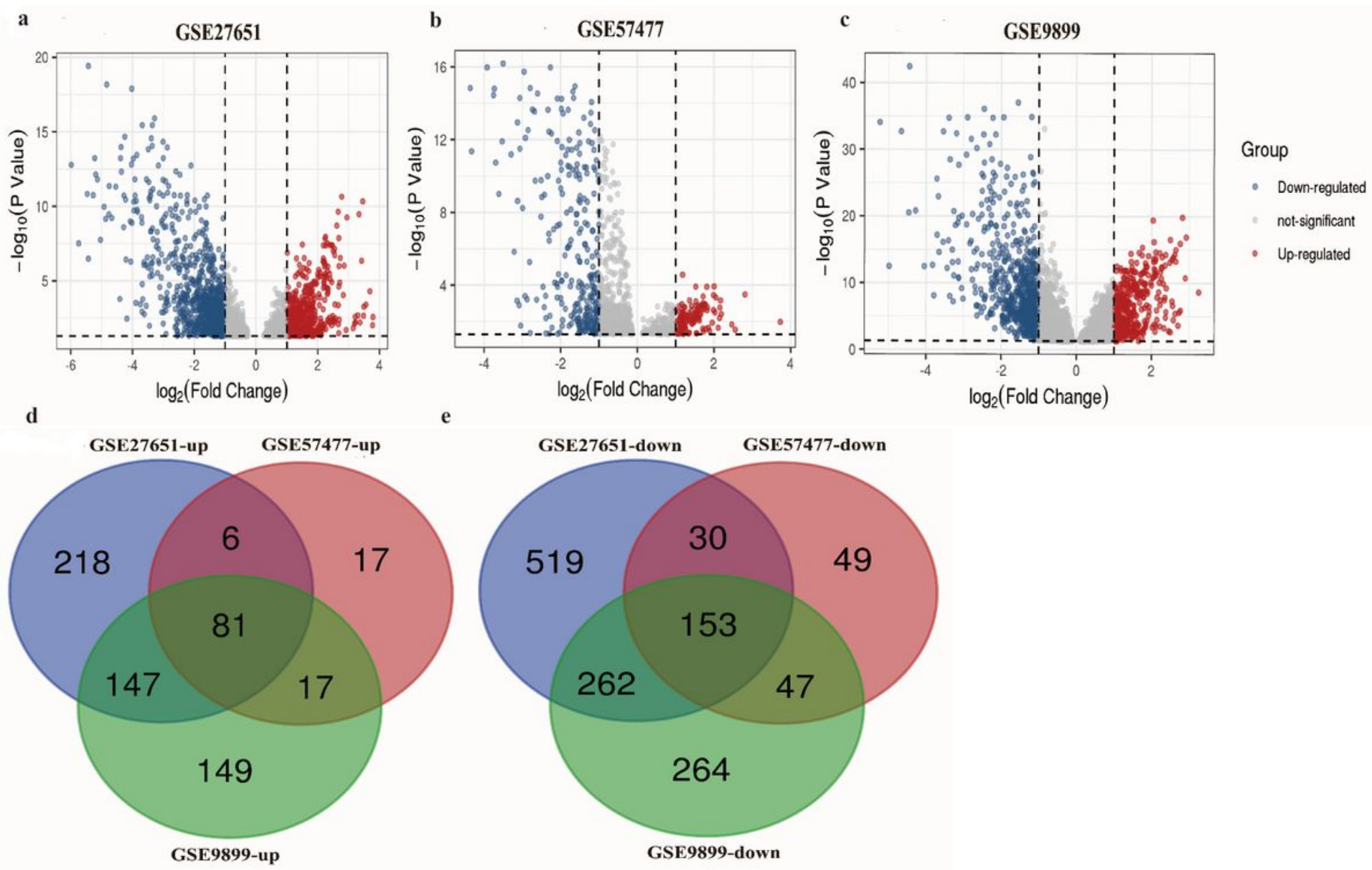

Figure 1

Identification of overlapping DEGs. Volcano plots of gene expression profile data in a GSE27651, b GSE57477, and c GSE9899, respectively. Venn plots of d upregulated and e downregulated overlapping DEGs among GSE27651, GSE57477, and GSE9899 datasets. 

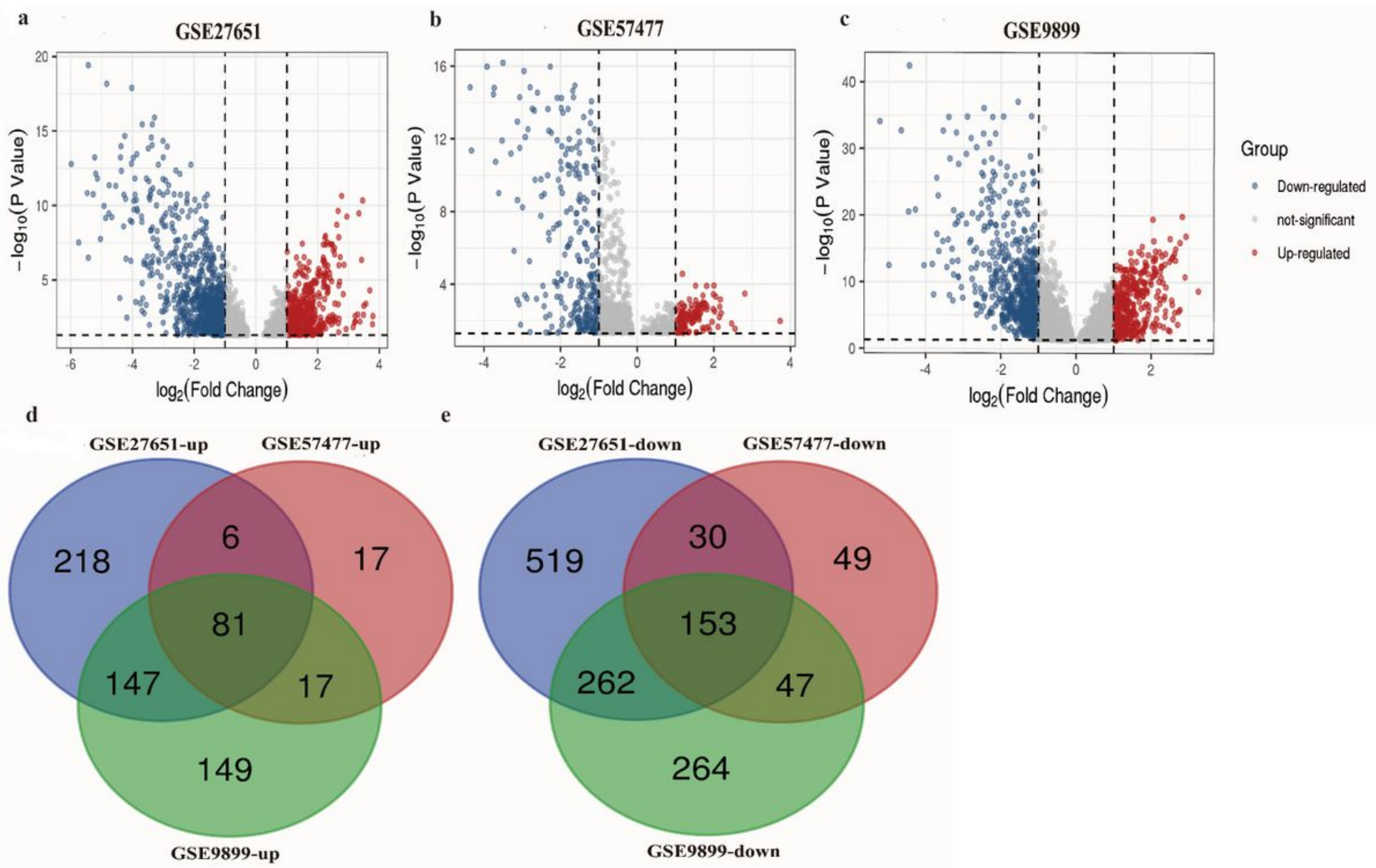

\section{Figure 1}

Identification of overlapping DEGs. Volcano plots of gene expression profile data in a GSE27651, b GSE57477, and c GSE9899, respectively. Venn plots of d upregulated and e downregulated overlapping DEGs among GSE27651, GSE57477, and GSE9899 datasets. 

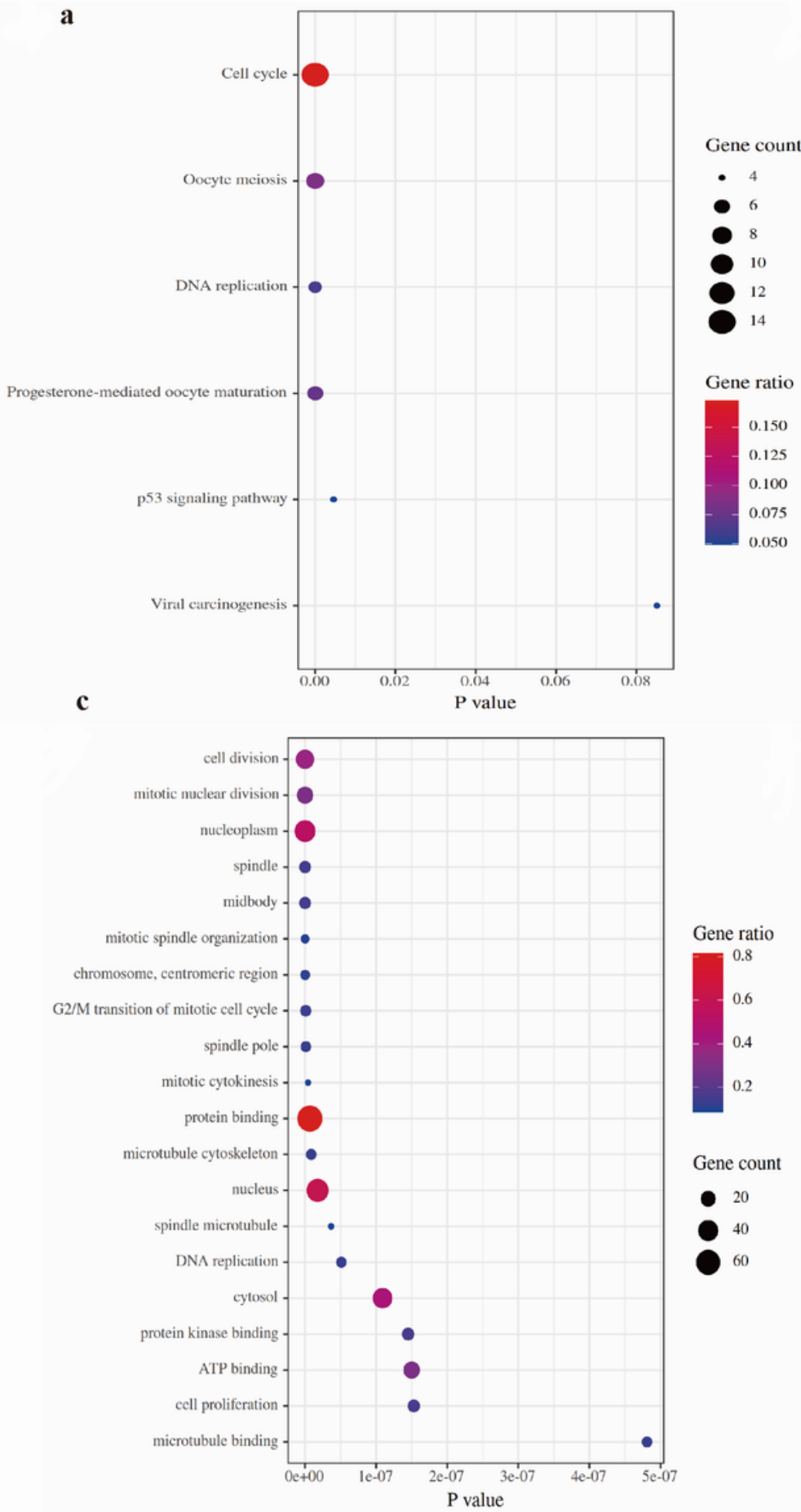

b
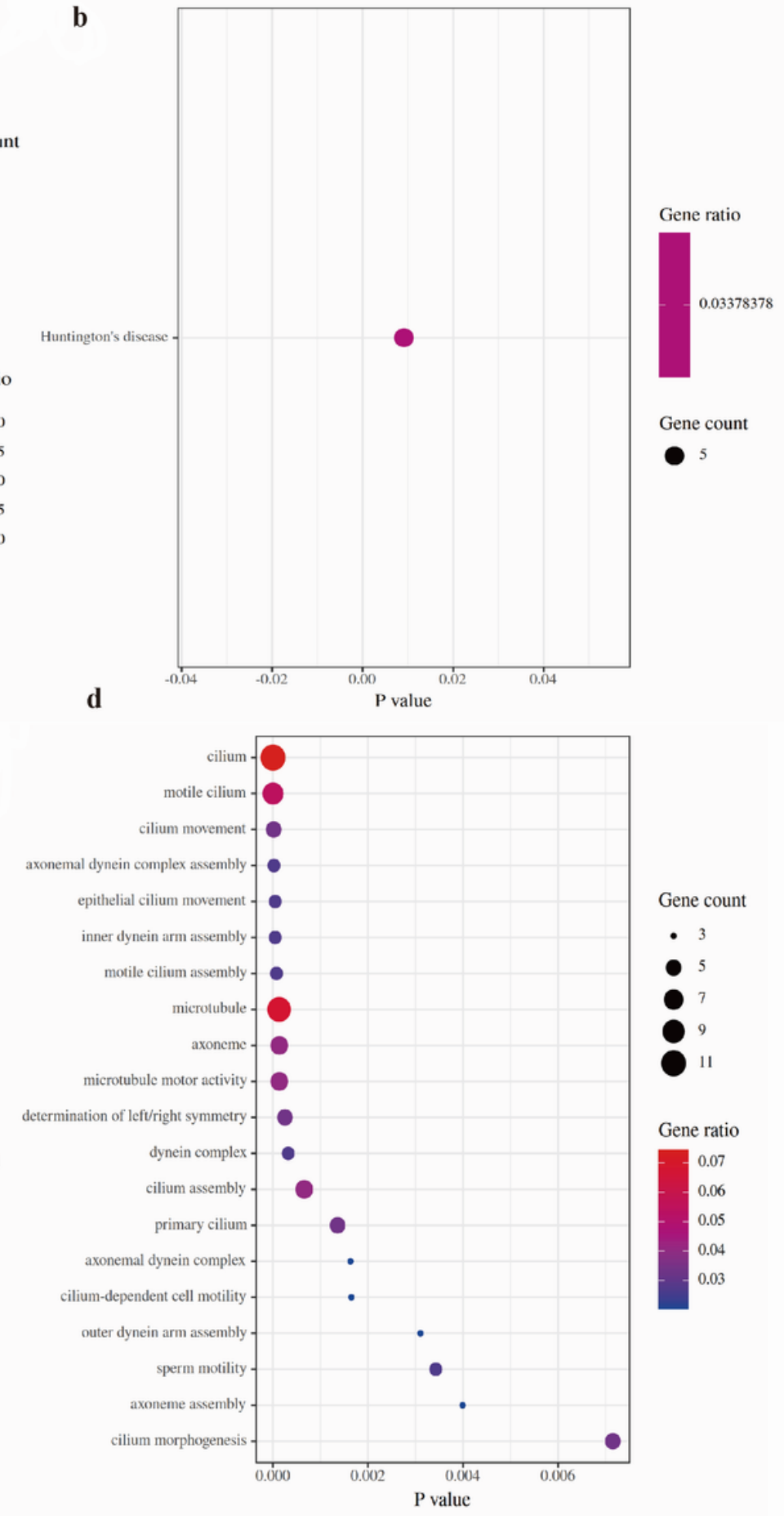

Figure 2

KEGG and GO analysis of the up- and downregulated DEGs. a KEGG analysis of upregulated genes associated with EOC. b KEGG analysis of downregulated genes associated with EOC. c GO analysis of upregulated genes associated with EOC. d GO analysis of downregulated genes associated with EOC. 

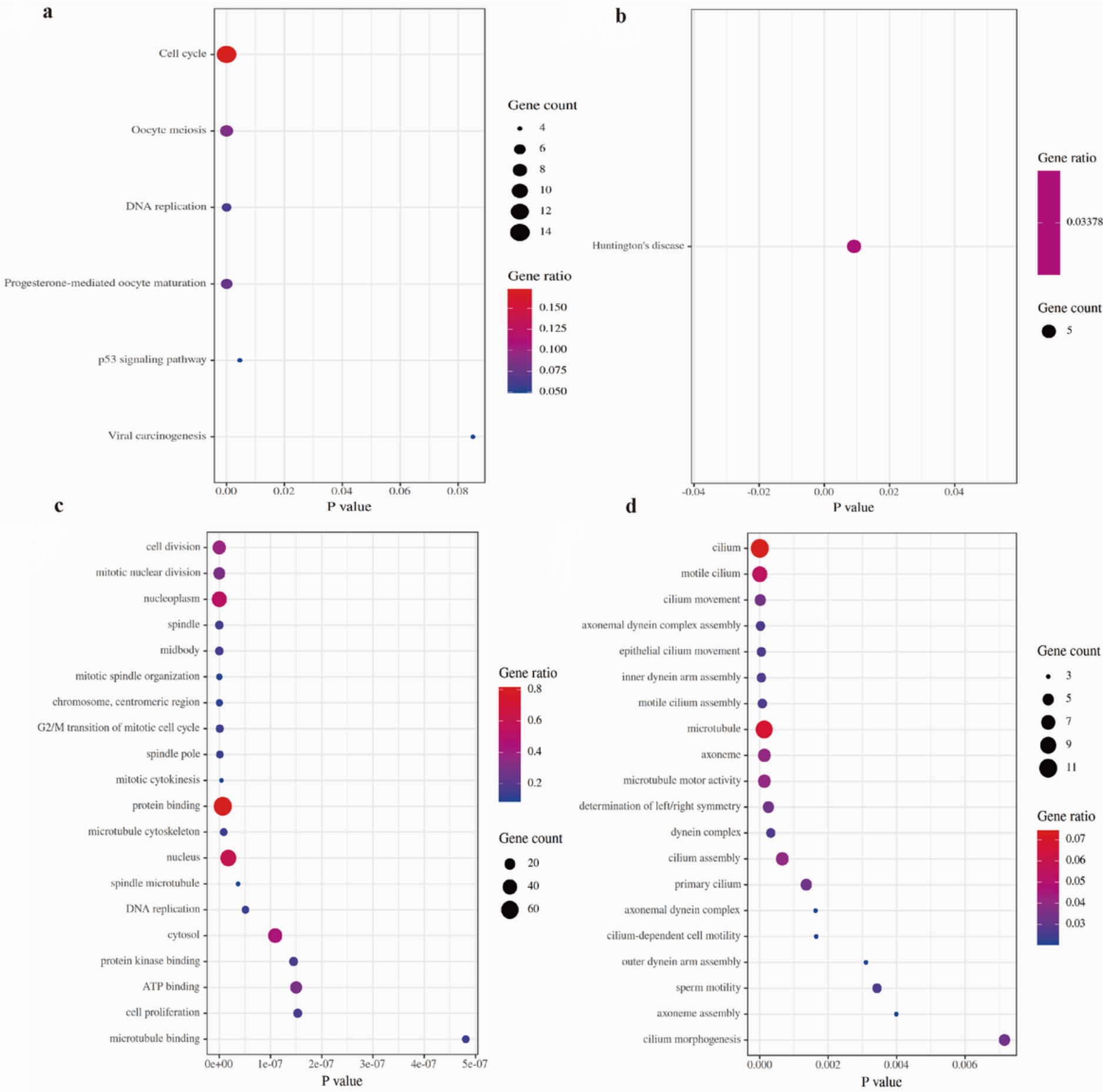

Figure 2

KEGG and GO analysis of the up- and downregulated DEGs. a KEGG analysis of upregulated genes associated with EOC. b KEGG analysis of downregulated genes associated with EOC. c GO analysis of upregulated genes associated with EOC. $d$ GO analysis of downregulated genes associated with EOC. 

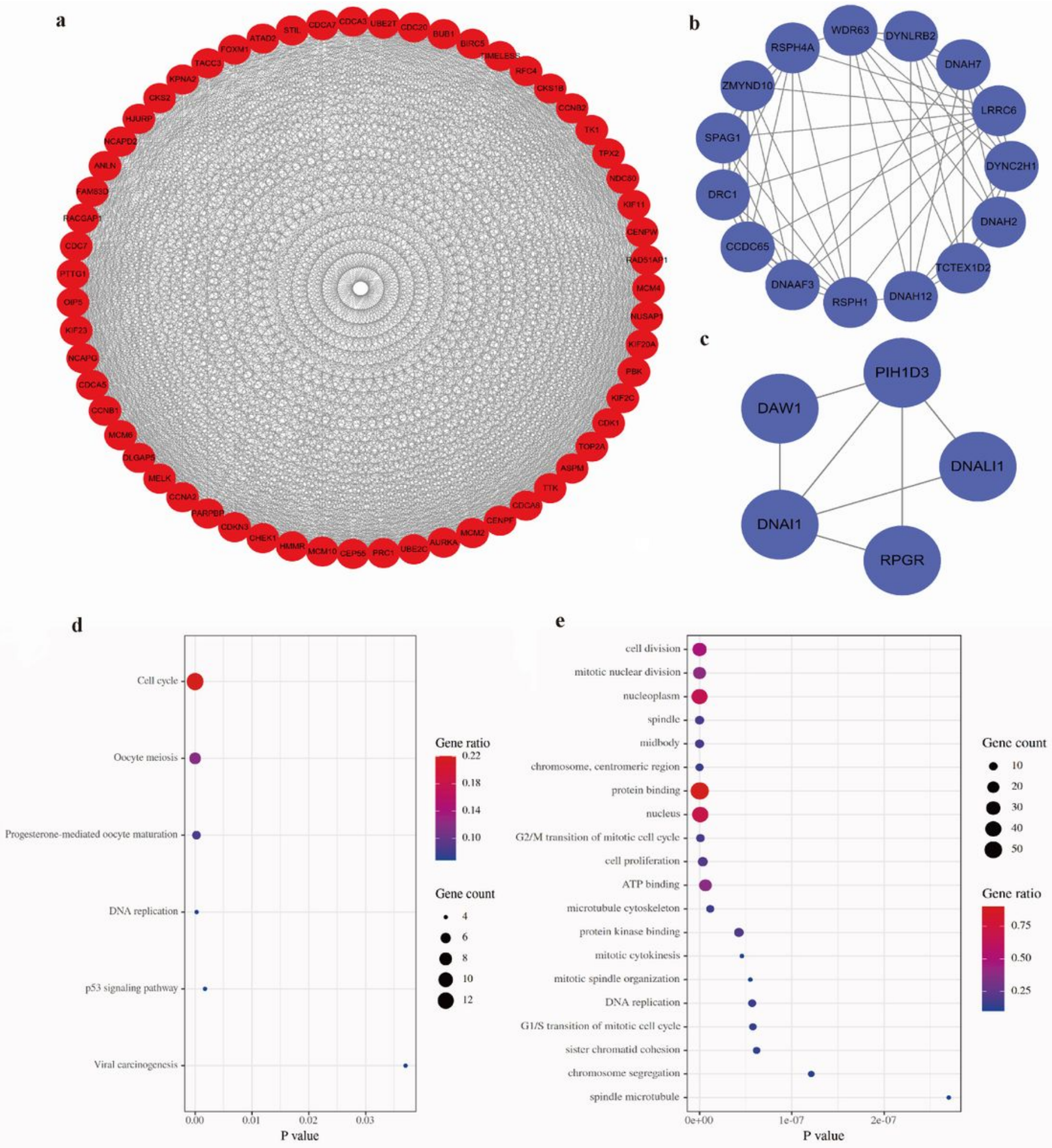

\section{Figure 3}

Significant modules selected from PPI network. a Cluster 1, b cluster 2, c cluster 3. (note: red nodes represent up-regulated genes, while blue node represent down-regulated gene); $\mathrm{d} \mathrm{KEGG}$ analysis of the genes in cluster 1. e GO analysis of the genes in cluster 1 . 

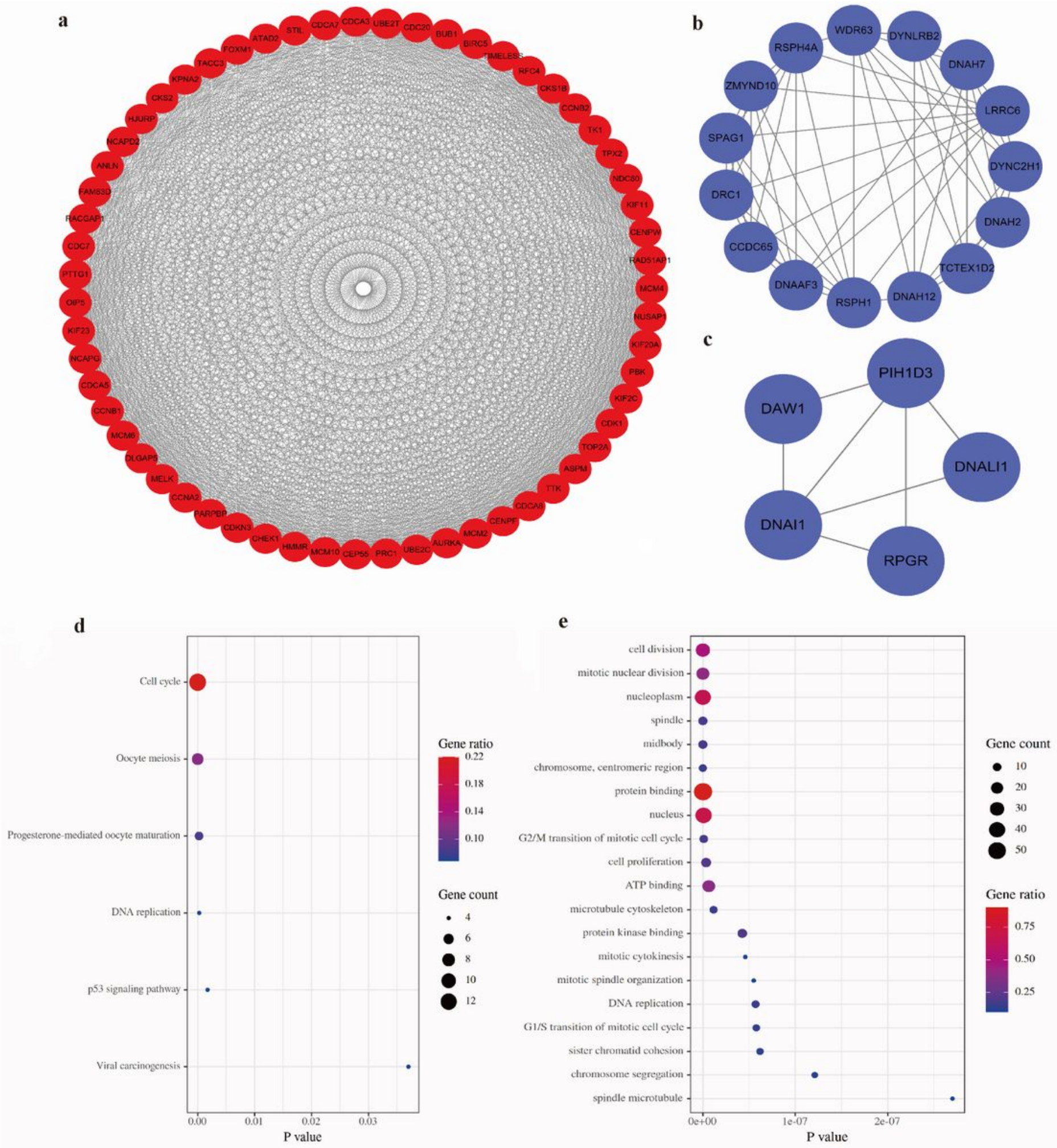

\section{Figure 3}

Significant modules selected from PPI network. a Cluster 1, b cluster 2, c cluster 3. (note: red nodes represent up-regulated genes, while blue node represent down-regulated gene); $\mathrm{d} \mathrm{KEGG}$ analysis of the genes in cluster 1. e GO analysis of the genes in cluster 1 . 

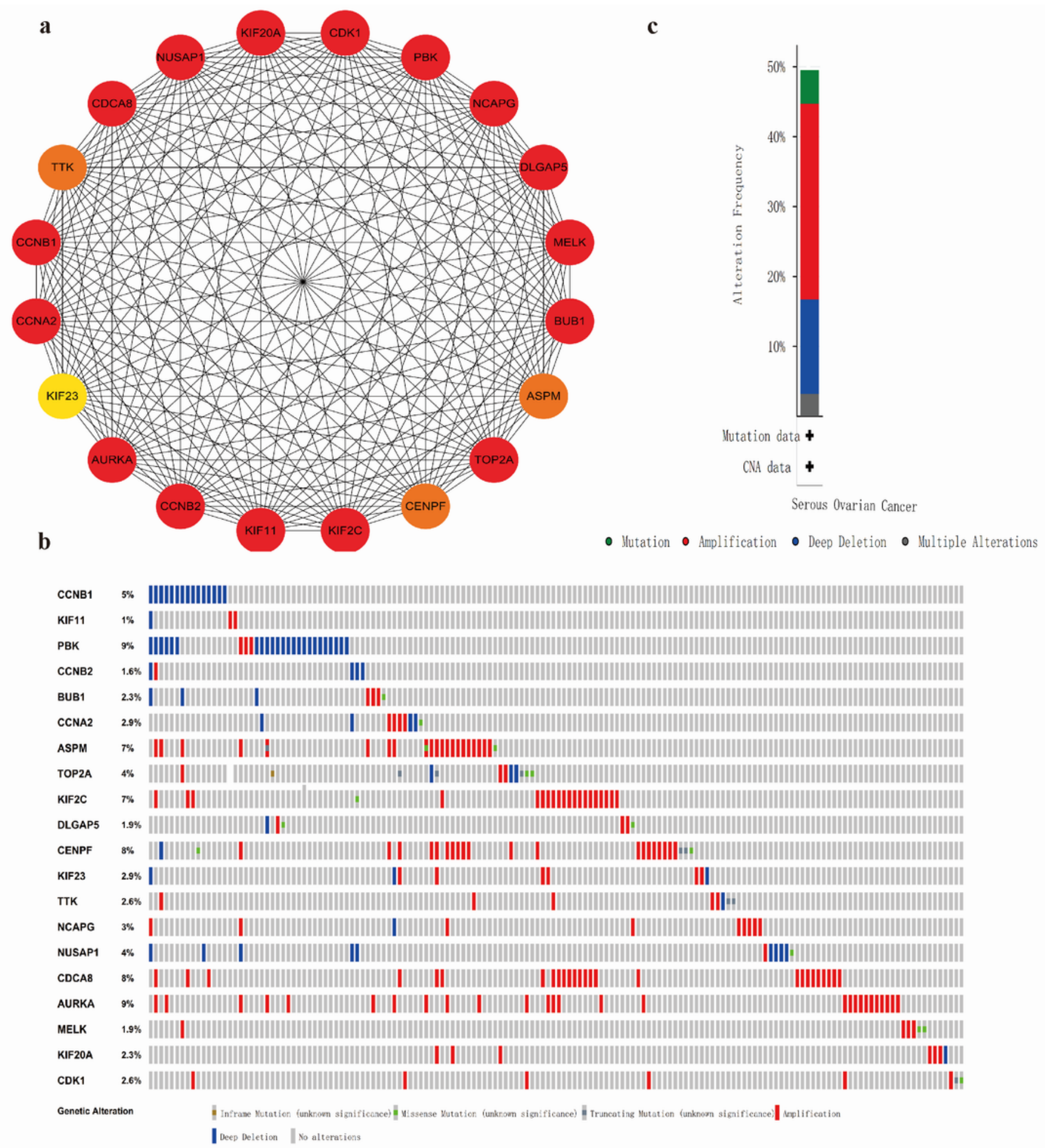

Figure 4

Hub Gene Identification and Information on the genetic alterations of the hub genes. a The top 20 hub genes were identified by cytoHubba. (note: the redder the nodes color, the higher the ranking). $b$ The genetic alterations related to the hub genes were shown through a visual summary across a set of ovarian serous cystadenocarcinoma samples (data from TCGA). c An overview of the alterations of the 20 hub genes in the genomics datasets of ovarian serous cystadenocarcinoma in the TCGA database. 


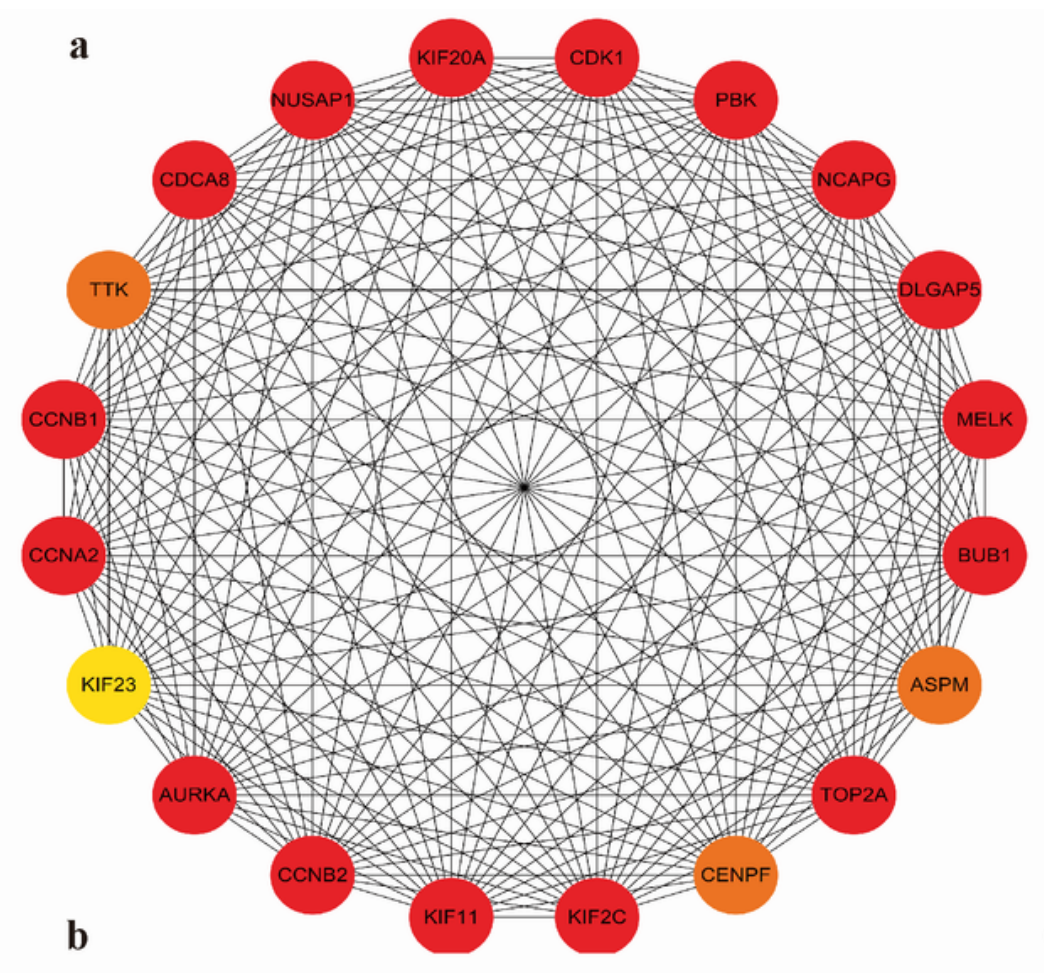

c

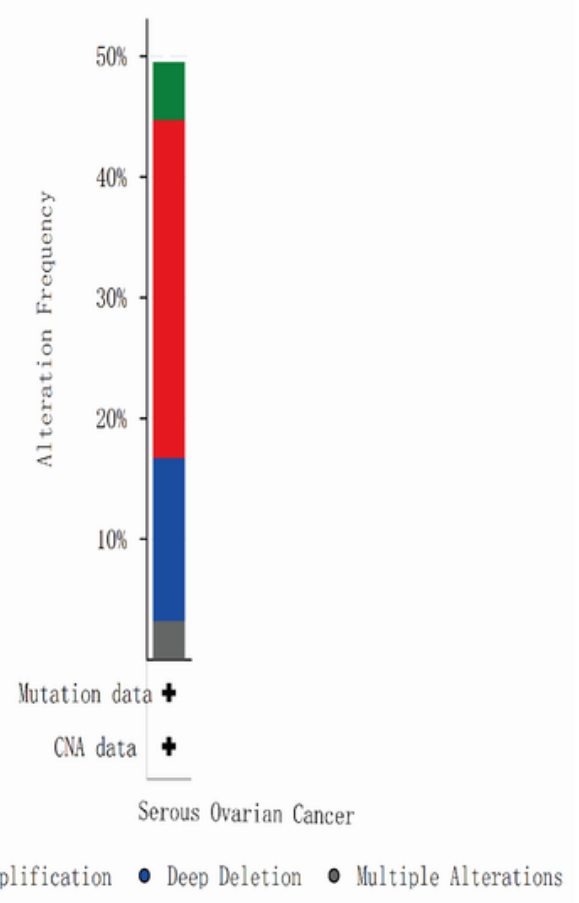

\section{Figure 4}

Hub Gene Identification and Information on the genetic alterations of the hub genes. a The top 20 hub genes were identified by cytoHubba. (note: the redder the nodes color, the higher the ranking). $b$ The genetic alterations related to the hub genes were shown through a visual summary across a set of ovarian serous cystadenocarcinoma samples (data from TCGA). c An overview of the alterations of the 20 hub genes in the genomics datasets of ovarian serous cystadenocarcinoma in the TCGA database. 

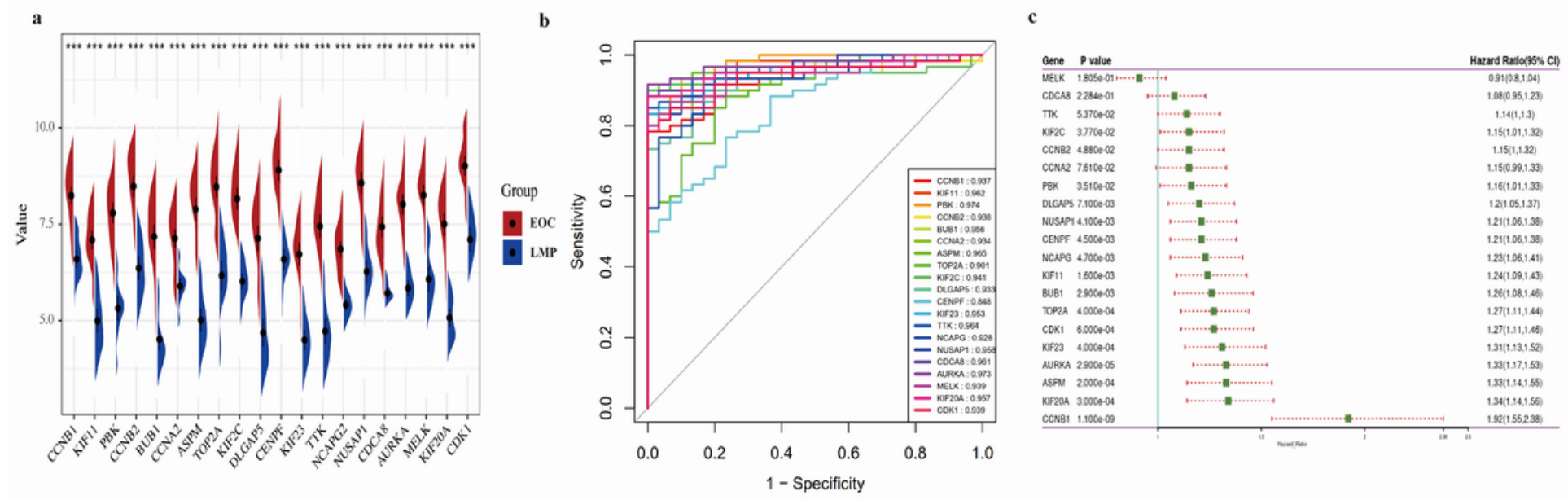

Figure 5

Hub gene validation. a The expression level of hub genes in LMP tumors and EOC samples in GSE12172. ${ }^{\star * \star} \mathrm{p}<0.001$. b ROC curve analysis was implemented to evaluate the capacity of 20 genes to distinguish EOC from LMP tumors. c Survival prognosis forest map of 20 hub genes related to prognosis in EOC patients. Each point in the forest plot represents the hazard ratio (HR) of the gene, and the line on both sides of the point represents the $95 \%$ confidence interval $(95 \% \mathrm{Cl})$.
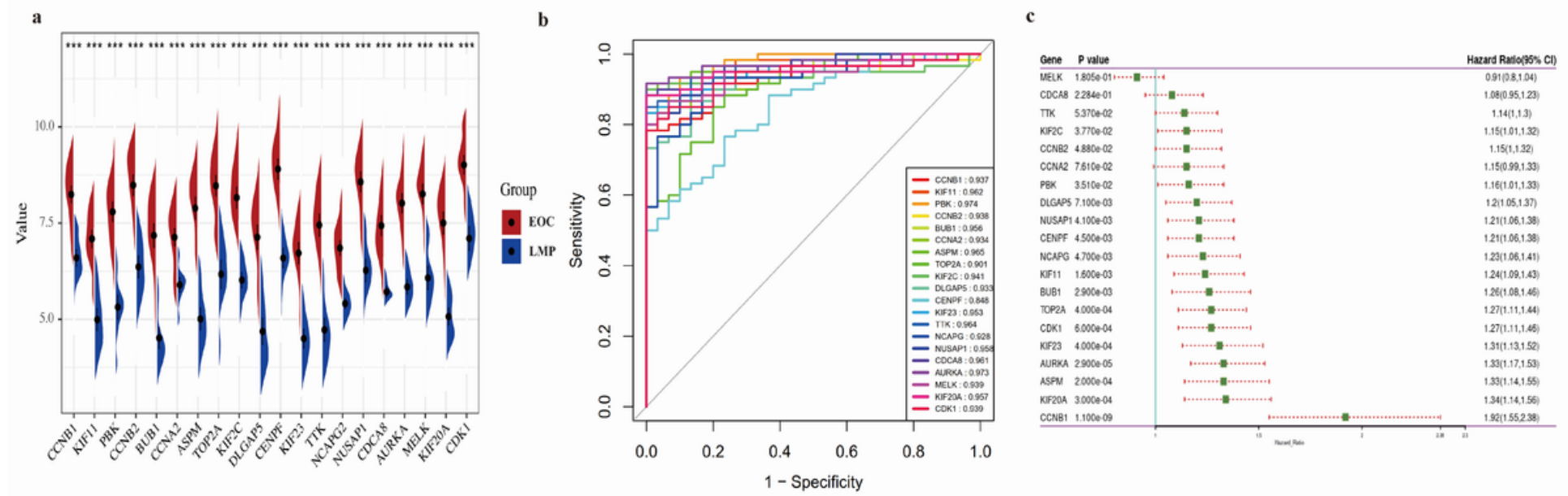

\section{Figure 5}

Hub gene validation. a The expression level of hub genes in LMP tumors and EOC samples in GSE12172. ${ }^{* * *} p<0.001$. b ROC curve analysis was implemented to evaluate the capacity of 20 genes to distinguish EOC from LMP tumors. c Survival prognosis forest map of 20 hub genes related to prognosis in EOC patients. Each point in the forest plot represents the hazard ratio (HR) of the gene, and the line on both sides of the point represents the $95 \%$ confidence interval $(95 \% \mathrm{Cl})$. 

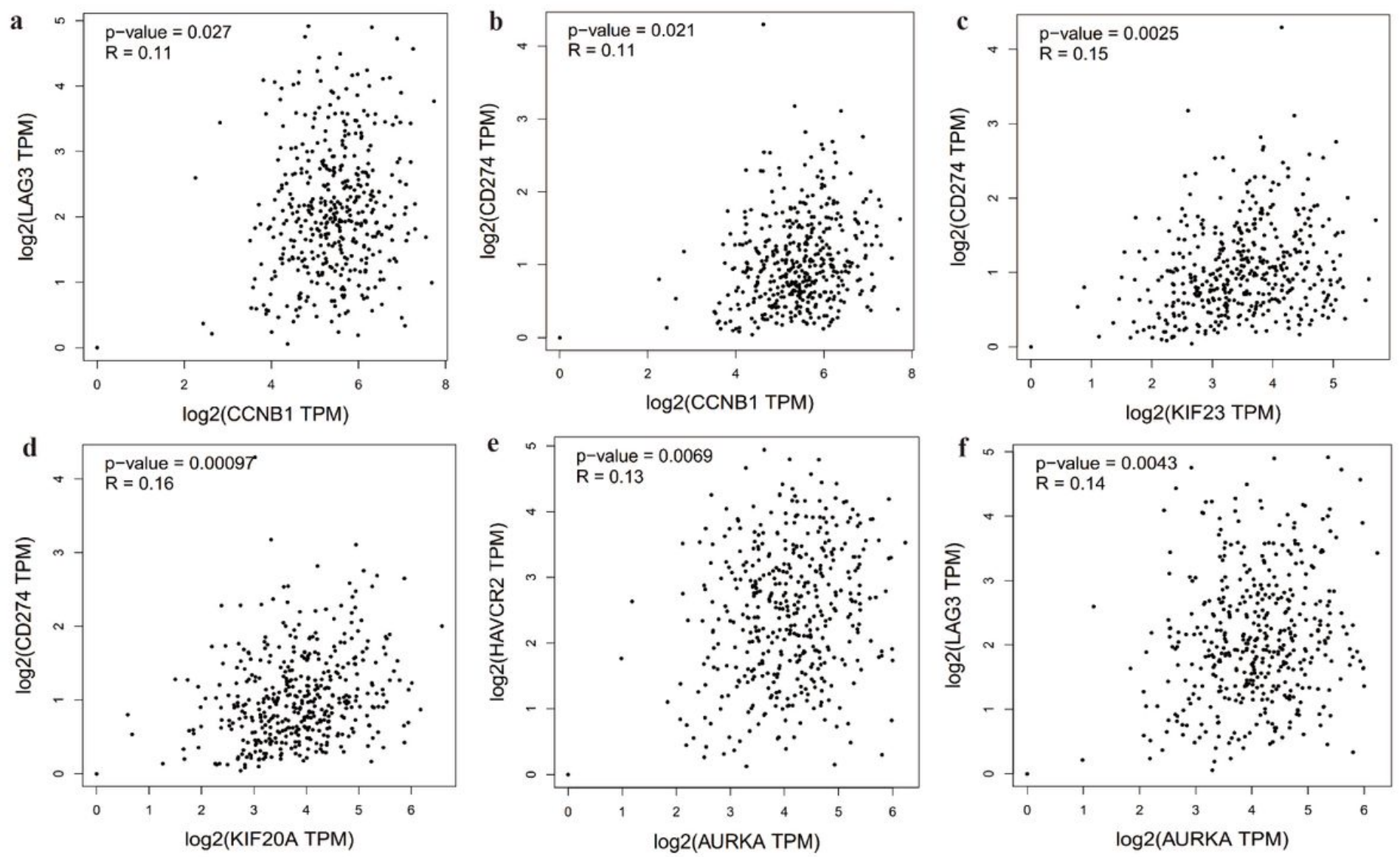

Figure 6

The positive correlation between the level of different immune checkpoint proteins and the expression of $a, b$ CCNB1, c KIF23, d KIF20A, e, f AURKA in EOC. 

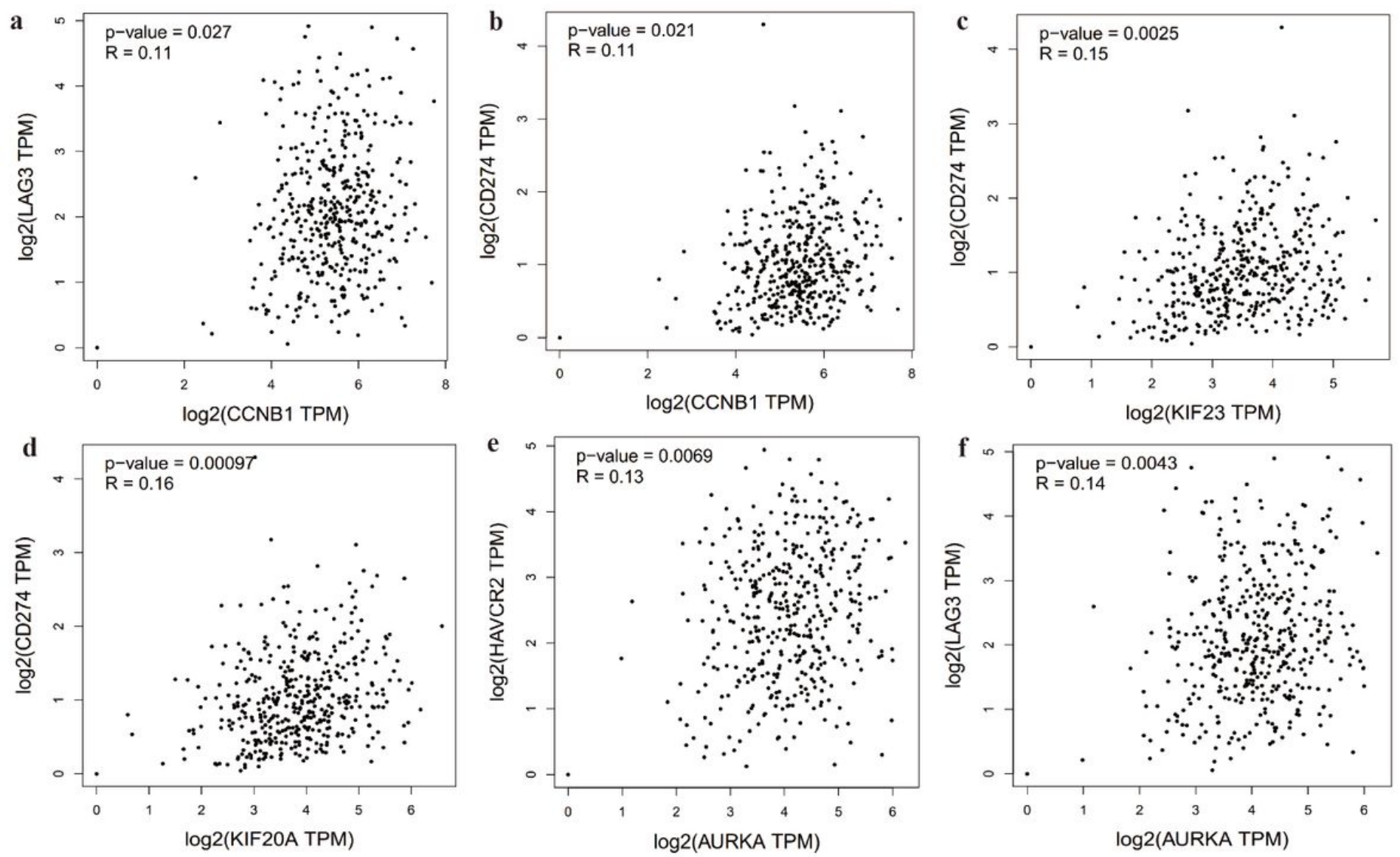

Figure 6

The positive correlation between the level of different immune checkpoint proteins and the expression of $a, b$ CCNB1, c KIF23, d KIF20A, e, f AURKA in EOC. 


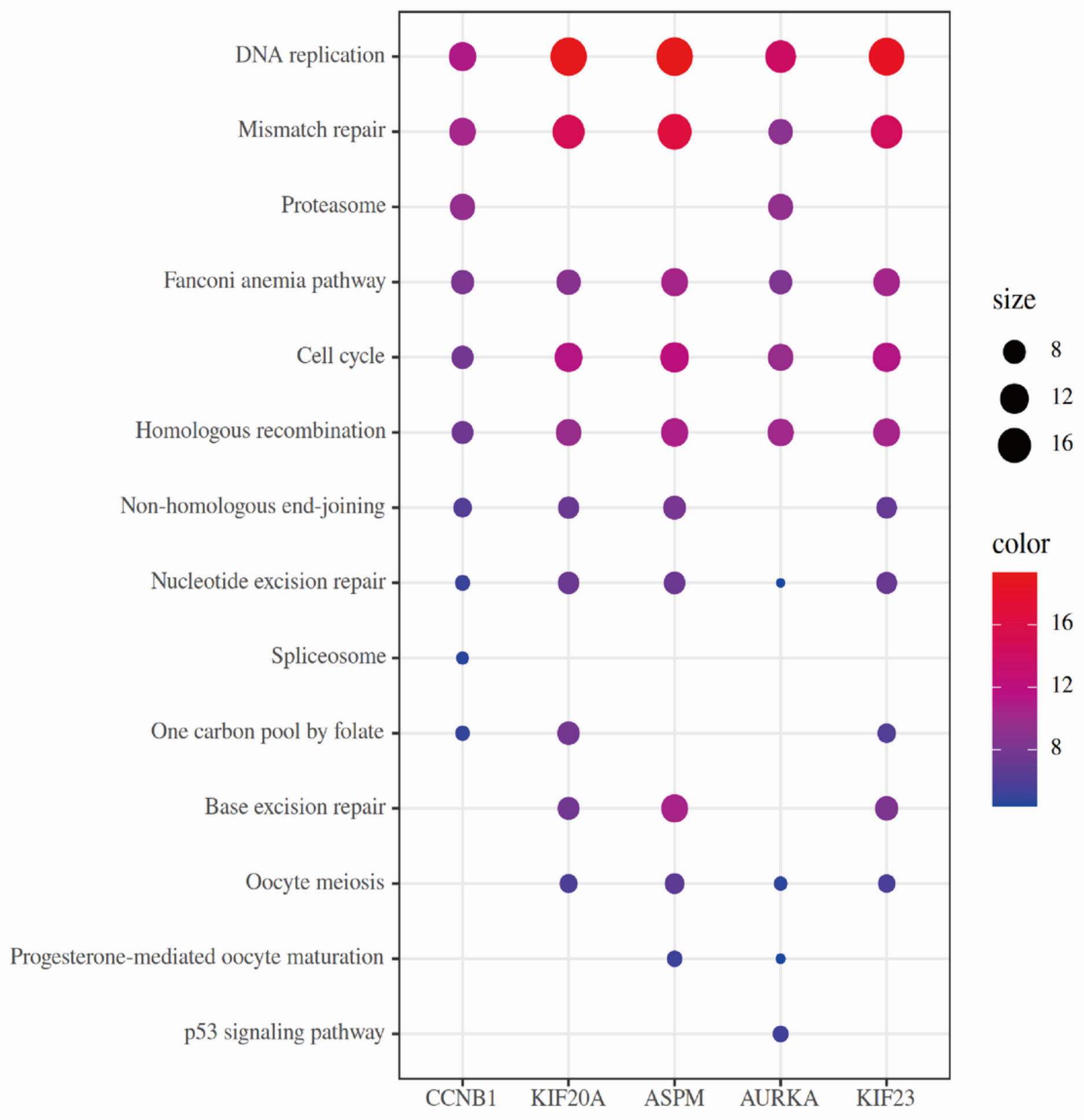

Figure 7

KEGG analysis of 5 core genes. 


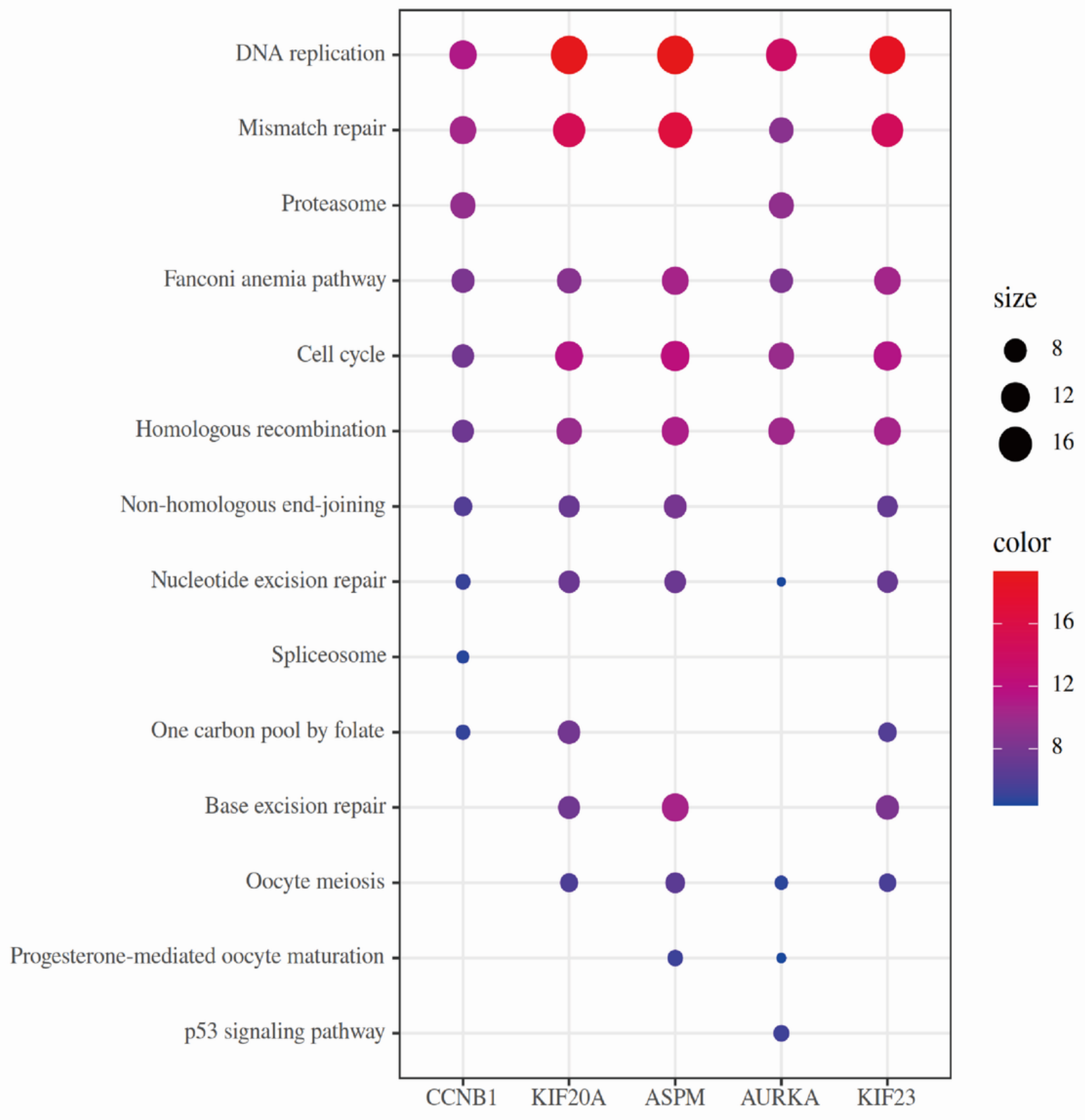

Figure 7

KEGG analysis of 5 core genes. 


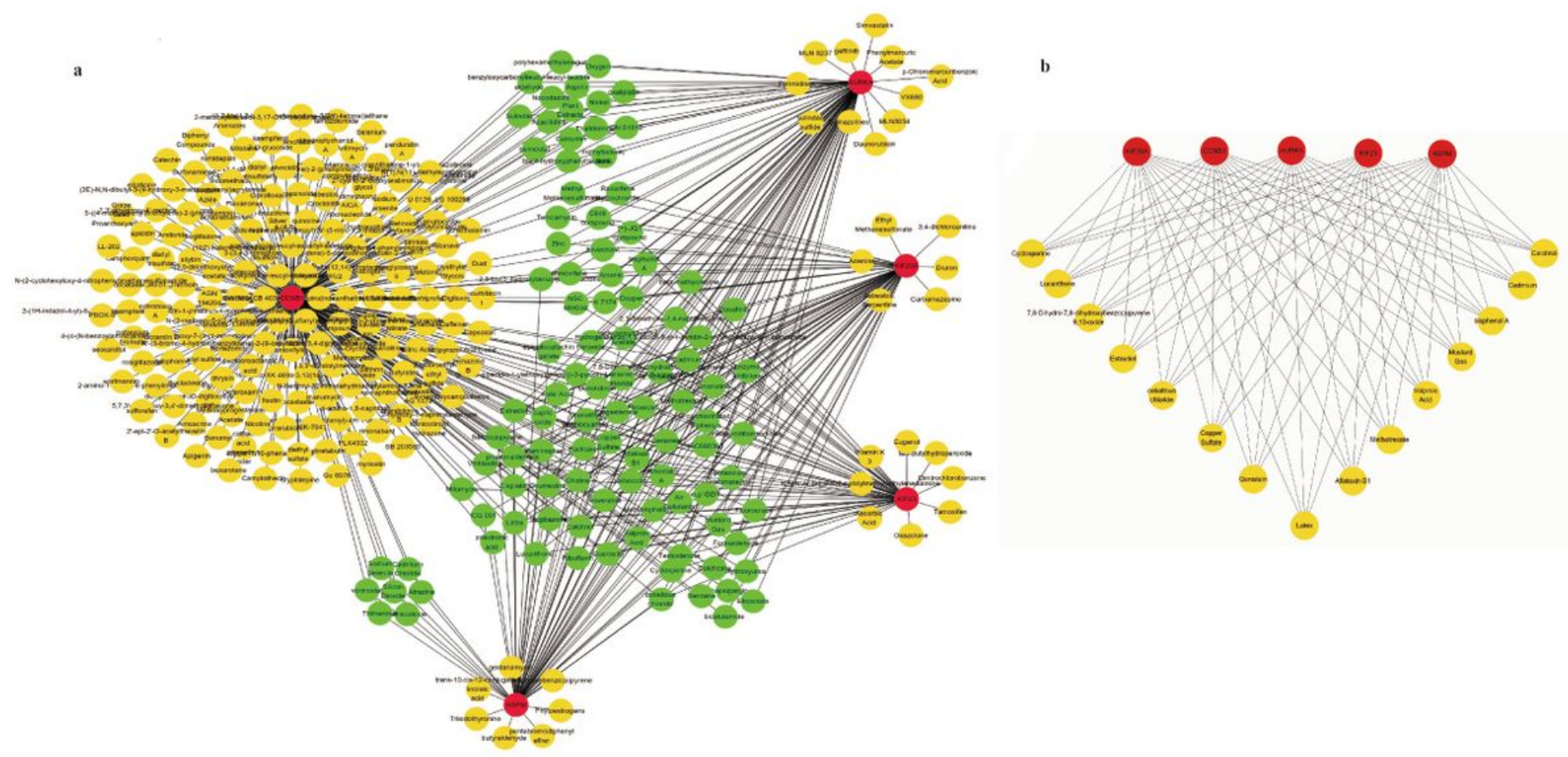

Figure 8

Chemical-core gene network analysis. a Interaction network between core genes and chemicals. b The top 15 chemicals screened by Cytoscape were related to all five core genes. Core genes are presented in red circles, whereas related chemicals are shown in yellow and green circles.

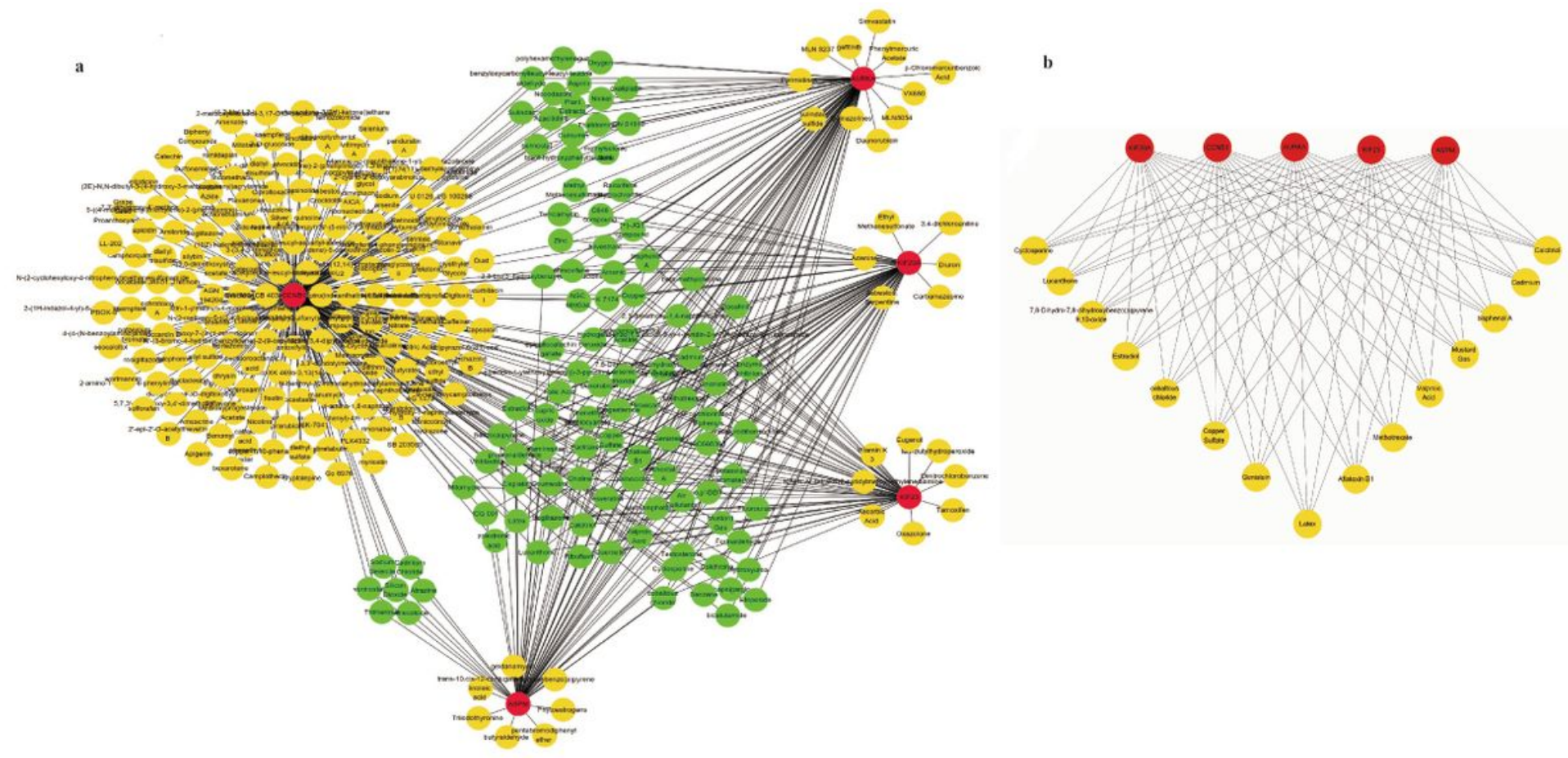

Figure 8

Chemical-core gene network analysis. a Interaction network between core genes and chemicals. b The top 15 chemicals screened by Cytoscape were related to all five core genes. Core genes are presented in red 
circles, whereas related chemicals are shown in yellow and green circles.

\section{Supplementary Files}

This is a list of supplementary files associated with this preprint. Click to download.

- TableS1.xIsx

- TableS1.xIsx

- TableS2.xIsx

- TableS2.xlsx 